\title{
Time-course of transcriptome response to respiratory syncytial virus infection in lung epithelium cells
}

\author{
S. AMPUERO ${ }^{1}$, R. ANDAUR ${ }^{1}$, M. MILANO ${ }^{1}$, M. MORENO ${ }^{2}$, L. LIZAMA ${ }^{1}$, C. LARRAÑAGA ${ }^{1}$, U. URZÚA ${ }^{3}$
}

\begin{abstract}
${ }^{1}$ Virology Program, Institute of Biomedical Sciences, Faculty of Medicine, University of Chile; Postal address 8380453, Independencia 1027, Independencia, Santiago, Chile; ${ }^{2}$ Laboratory of Oncology and Molecular Genetics, Coloproctology Unit, Clinica Las Condes, Santiago, Chile; Postal address 7591046, Santiago, Chile; ${ }^{3}$ Department of Basic and Clinical Oncology, Faculty of Medicine, University of Chile, Postal adress 8380453, Santiago, Chile
\end{abstract}

\begin{abstract}
Summary. - Respiratory syncytial virus (RSV) is the major cause of acute lower respiratory tract infection in infants. Winter outbreaks in Chile result in $5 \%$ of infected children hospitalized, with $0.01 \%$ mortality. Increased evidence indicates that viral and host factors modulate the severity of infection. Using DNA microarrays, we characterized the genome-wide transcriptional response of lung mucoepidermoid cells (NCI-H292) at 0, 24, 48, 72 and 96 hours post-infection (hpi) with a single dose of RSV/A. During the whole studied period, a bi-phasic gene expression profile was observed by a total of 330 differentially expressed genes. About $60 \%$ of them were up-regulated between $24-72$ hpi and then turned-off at 96 hpi. This transient, early gene expression pattern was significantly enriched in biological processes like interferon signaling, antigen processing and presentation, double-stranded RNA binding and chemokine activity. We detected 27 common genes up-regulated between 24-72 hpi, from which IFIT1, IFI44, MX1, CXCL11 and OAS1 had the highest expression. The second pattern comprised over 120 genes, which remained silenced until $72 \mathrm{hpi}$, but were steeply up-regulated by $96 \mathrm{hpi}$. Biological processes of this late-response profile included cell cycle division and microtubule cytoskeleton organization. Conversely, the genes belonging to virus response pathway showed a decreased expression at $96 \mathrm{hpi}$. We conclude that RSV induces an early innate immune activation profile response until $72 \mathrm{hpi}$. Thereafter, the viral response is inhibited, leading to host cell recovery. The presented cellular model allows to study the specific pathways involved in elimination of infection at prolonged time intervals and their subsequent analysis in severe RSV disease of infants and/or older adults.
\end{abstract}

Keywords: RSV; NCI-H292 cells; microarrays; time-course; gene expression profile

\section{Introduction}

Respiratory syncytial virus (RSV) is recognized as the main respiratory pathogen causing illness in children, presenting a higher morbidity in infants younger than 6 months and also in elderly population. RSV causes illness ranging

E-mail: sampuero@u.uchile.cl; phone: +56-2-29786961.

Abbreviations: $\mathrm{HCL}=$ hierarchical clustering; hpi = hour(s) postinfection; IFA = indirect immunofluoresce assay; $\mathrm{Fc}=$ fold change; LTRI = lower respiratory tract illness; RSV = respiratory syncytial virus; $\mathrm{SSC}=$ saline sodium citrate buffer from a mild upper respiratory tract to severe lower respiratory tract illness (LRTI), with bronchiolitis being its main clinical manifestation (Tregoning and Schwarze, 2010; Griffiths et al., 2017). Studies performed in our country showed that previously healthy term infants younger than 6 months of age hospitalized due to LRTI-RSV, developed varied clinical outcome severity, while $50 \%$ showed a severe outcome and $21 \%$ or less presented low severity outcome after hospitalization (Luchsinger et al., 2014). Different factors have been postulated to explain these differences, depending on the virus, the viral load, circulating genotypes and the host as immune response and genetic susceptibility (Ampuero et al., 2011; Luchsinger et al., 2014; Rusell et al., 2017). 
RSV belongs to the family Paramyxoviridae, the genus Pneumovirus. It is an enveloped virus; its genome consists of a linear, non-segmented negative single-strand RNA (ssRNA), which encodes for 10 subgenomic mRNAs and 11proteins: NS1, NS2, N, P, M, SH, F, G, M2-1, M2-2, L. Infection occurs by direct contact with aerosol containing viral particles. RSV replicates in the nasopharynx, its incubation period lasts $4-5$ days and viral excretion can be detected between 1-21 days. RSV propagates down to the lower respiratory tract in just 1-3 days. The virus disseminates from cell to cell without contacting the extracellular medium and forms syncytia, a known RSV cytopathic effect (Collins et al., 2013). The direct replication of RSV would not be implied in the disease onset, as histopathological and in vitro models show rather the inflammatory mediators of immune response to be associated with RSV pathogenesis and disease development (Welliver et al., 2008; Collins and Melero, 2011; Rusell et al., 2017). After infection, the RSVinfected cells detect viral components, especially viral RNA and intermediates of virus replication, through receptors as the Toll-like receptors (TLRs), retinoic acid-inducible geneI-(RIG-I-) like receptors (RLRs), and nucleotide-binding oligomerization domain-(NOD-) like receptors (NLRs) (Gouba et al., 2013; Kim and Lee, 2014). Activation of these receptors triggers a signaling pathway that allows activation of gene expression of pro-inflammatory cytokines and chemokines and interferon $\alpha$ and $\beta$ (Mukherjee and Lukacs, 2013). In turn, the response to interferon modulates the activation of interferon-stimulated genes (ISGs) (Takaoka and Yanai, 2006). Altogether, all these immune response signals allow the triggering of antiviral response at the cellular level and systemically attract immune cells to the infection site while activating the acquired immune response. On the other hand, the virus itself is able to modulate this response. It has been established that RSV proteins NS1 and NS2 interfere with the activation of ISGs, suppress dendritic cell maturation and cytokines production (Barik, 2013; Schmidt and Varga, 2017). Nowadays, there are no effective antivirals or anti-RSV vaccines that have a real impact on diminishing the number of infected subjects or an attenuation of the severity of the disease caused by RSV. Only Palivizumab, a humanized monoclonal antibody, is recommended for prophylaxis in infants at high-risk to develop severe RSV disease (Turner et al., 2014).

In spite of multiple studies regarding RSV infection, some aspects of RSV-host interaction are still unclear. Changes in gene expression after RSV infection using microarray platforms have delivered a great amount of information of pathways and molecules involved during the infection. Moreover, the use of cell lines susceptible to RSV infection, although far from the global response of the individual, allows designing controlled studies and to specifically focus on cell and molecular pathways (Zhang et al., 2001; Fjaerli et al.,
2006; Janssen et al., 2007; Martínez et al., 2007; Mayer et al., 2007; Huang et al., 2008; Mejías et al., 2013). Several studies have analyzed the gene expression profile after RSV infection in cell models at early times after infection. However, the majority of symptomatic cases consult after 2 to 3 days of the onset of symptoms, for this reason the establishment of in vitro models that cover the time-course of RSV infection could contribute to better understanding of the pathogenesis of this virus. In addition, considering that infants with an RSV infection without known risk factors can develop conditions of variable severity, expression studies in this specific population would indicate the pathways that could be studied more specifically using a suitable cellular model. Our aim was to analyze variations in gene expression of a pulmonary epithelial cell line, NCI-H292, infected with RSV/A at different times after infection using Human Exonic Evidence Based Oligonucleotide (HEEBO) array.

\section{Materials and Methods}

Cells and culture conditions. The human lung epithelial cell line NCI-H292 was purchased from the American Type Culture Collection (CRL-1848, MD, USA) and grown at $37^{\circ} \mathrm{C}$ in $5 \% \mathrm{CO}_{2}$ in RPMI-1640 medium (HyClone) supplemented with 10\% FBS, $100 \mathrm{U} / \mathrm{ml}$ penicillin, $100 \mu \mathrm{g} / \mathrm{ml}$ streptomycin, $10 \mathrm{mmol} / \mathrm{l}$ HEPES free acid and 1x MEM-non essential aminoacids solution.

Preparation of the RSV inoculum.RSV/A/Tracy (Luchsinger et al., 2012) was propagated in MA104 cells as previously described (Chen et al., 2002).Virus stocks were obtained within 3 days after infection and then stored in $1 \mathrm{ml}$ aliquots at $-80^{\circ} \mathrm{C}$. For plaque titration of RSV aliquots, $70 \%$ confluent NCI-H292 cells were grown in 6-well plates with RPMI-1640 2X supplemented with2\% FBS. Then $0.5 \mathrm{ml}$ serial dilutions of virus stocks were added and incubated at $37^{\circ} \mathrm{C}$. After $1 \mathrm{~h}, 2.5 \mathrm{ml}$ of $1.2 \%$ agarose was added to each well and the plates were incubated at $37^{\circ} \mathrm{C}$ in $\mathrm{CO}_{2}$ incubator for 7 days. The plaques were visualized and counted using methyl violet staining.

RSV infection, cell harvesting and RNA extraction. NCI-H292 cells grown to $70 \%$ confluence were treated with a $1 \mathrm{x}$ PBS, $50 \mathrm{mmol} / \mathrm{l}$ EDTA pH 8.0 solution for $10 \mathrm{~min}$ at $37^{\circ} \mathrm{C}$ to release them from culture flask surface. Cell suspension was centrifuged at $800 \mathrm{x}$ g for $10 \mathrm{~min}$. The resulting cell pellet, $5 \times 10^{6}$ cells, was resuspended in $2 \mathrm{ml}$ of RPMI-1640 medium and infected with $4.8 \times 10^{5} \mathrm{PFU}$ of RSV-A strain (approximately $5 \log \mathrm{PFU} / \mathrm{ml}$ ), getting a MOI of 0.1 . Cultures were incubated at $37^{\circ} \mathrm{C}$ in $5 \% \mathrm{CO}_{2}$ and cells were harvested at $0,24,48,72$ and 96 hours post-infection (hpi). Control, uninfected cultures were set-up simultaneously and cells collected at the indicated times. Total RNA was extracted with Trizol (GIBCO BRL Life Technologies), treated with RNase-free DNase (QIAGEN) and cleaned up with the RNeasy Mini Kit (QIAGEN). RNA integrity was assessed by measuring the $28 \mathrm{~S} / 18 \mathrm{~S}$ ratio in $1 \%$ 
agarose gels. RNA concentration was determined by $\mathrm{A}_{260} / \mathrm{A}_{280} \mathrm{~nm}$ spectrophotometry (Epoch, Biotek Instruments).

$R S V$ detection. Confirmatory indirect immunofluorescence assay (IFA) for RSV infection was performed in cell cultures as described using monoclonal antibodies, $133-1 \mathrm{H}$ and $92-11 \mathrm{C}$, that react with the fusion protein (F), (kindly provided by L. Anderson, Centers for Disease Control and Prevention, Atlanta, Georgia) (Avendaño et al., 2003). Total RNA was extracted from supernatant of infected cell cultures. Qualitative detection of RSV was done with real-time reverse transcription polymerase chain reaction (real time RT-PCR) as described previously (Luchsinger et al., 2014).

cDNA labeling and microarray hybridization. Equal amounts of RNA isolated from infected and uninfected cultures were fluorescence labeled in parallel. Namely, $15 \mu \mathrm{g}$ of DNAse-treated purified RNA samples were tagged either with Cy3-dUTP (GE Healthcare) or Cy5-dUTP (GE Healthcare) by reverse transcription using Superscript II Reverse Transcriptase (Invitrogen). Dye swap was conducted for each sample pair analyzed. Labeled cDNAs were mixed and cleaned up with Mini Elute PCR columns (QIAGEN). Purified cDNA mixture was combined with an equal volume of hybridization solution (1x SSC, 50\% deionized formamide, $0.1 \%$ SDS and $20 \mu \mathrm{g}$ of salmon sperm DNA), incubated at $95^{\circ} \mathrm{C}$ for $3 \mathrm{~min}$ and then at $37^{\circ} \mathrm{C}$ for $5 \mathrm{~min}$. This solution was deposited onto HEEBO microarrays (MI, Microarrays.Inc), covered with LifterSlip coverslips and incubated at $42^{\circ} \mathrm{C}$ for $18 \mathrm{~h}$ in Telechem hybridization cassettes. Then, microarray slides were washed with solutions of decreasing salt concentration ( $2 \mathrm{x}$ SSC plus $0.1 \%$ SDS; $1 \mathrm{x}$ SSC; $0.2 \mathrm{x}$ SSC), dried and immediately scanned in a ScanArray Lite (PelkinElmer) set at $90 \%$ of laser power and $60-70 \%$ of PMT gain. TIFF microarray images were analyzed with the GenePixPro6.0software (Molecular Devices).
Data processing, statistical and functional analysis. GPR files and composite microarray images were deposited to the NCI's microarray database (mAdb; http://madb.nci.nih.gov/). Microarray data was intra and inter-slide normalized by the local print-tip Loess method with background subtraction using the DNMAD tool (http://asterias.bioinfo.cnio.es). An ANOVA test with false discovery rate (FDR) control was performed with the tool Pomelo II (http://pomelo2.bioinfo.cnio.es). The time course analysis and hierarchical clustering (HCL) were performed with TMEV tool v4.7 using average linkage and leaf order optimization as linkage method and Euclidean distance as distance metric. Differentially expressed genes $(\mathrm{p}<0.01)$ in response to viral infection were filtered out with $\log _{2}$ fold-change $(\mathrm{Fc}): \geq 1.0$ or $\leq-1.0$ for further biological significance analysis. Statistically significant gene ontology (GO) categories were obtained after the functional enrichment analysis using the WebGestalt online tool (www.webgestalt.org) with hypergeometric algorithm and Benjamini-Hochberg multiple testing correction. The common genes at different hpi were determined with Venn diagrams (http://bioinformatics.psb.ugent.be/webtools/ Venn).

Relative quantification of selected genes by real time RT-PCR. A real time RT-PCR assay based on SYBR-Green detection was used to confirm the relative gene expression of a selected set of genes. Total RNA was obtained for each viral infection as previously described, treated with RNase-free DNase (QIAGEN) and quantified by measuring absorbance at $260 \mathrm{~nm}$ (Epoch, Biotek Instruments). The cDNAs were obtained from $1 \mu \mathrm{g}$ RNA using M-MLV Reverse Transcriptase (Promega) and random primers (Promega) according to the manufacturer's guidelines. Real time RT-PCR was performed using specific primers designed from NCBI sequences and the software Beacon Designer 8.02 (PREMIER Biosoft). The

Table 1. Forward and reverse gene-specific primers and thermal cycling conditions for real time RT-PCR

\begin{tabular}{lllc}
\hline Gene symbol & GenBank Acc. No. & Forward (F) and reverse (R) primers & Thermal cycling conditions $^{*}$ \\
\hline B2M & NM_004048.2 & F: TGTAAGCAGCATCATGGA & $95^{\circ} \mathrm{C} \times 3 \mathrm{~s}$ \\
& & R: AGTGTAAGTGTATAAGCATATCAA & $53^{\circ} \mathrm{C} \times 20 \mathrm{~s}$ \\
HLA-A & NM_002116.2 & F: GAGATGGGAGCTGTCTTC & $95^{\circ} \mathrm{C} \times 3 \mathrm{~s}$ \\
& & R: CTCTTCCTCCTCCACATC & $60^{\circ} \mathrm{C} \times 10 \mathrm{~s}$ \\
HPRT1 & NM_00194.2 & F: GGTCAGGCAGTATAATCCA & $95^{\circ} \mathrm{C} \times 3 \mathrm{~s}$ \\
& & R: GCTTATATCCACACTTCGT & $58^{\circ} \mathrm{C} \times 20 \mathrm{~s}$ \\
IFI44 & NM_006417.2 & F: TCTGAGACGAATGCTATG & $95^{\circ} \mathrm{C} \times 3 \mathrm{~s}$ \\
& & R: CTTCTGTGATGTGAGGAA & $59^{\circ} \mathrm{C} \times 15 \mathrm{~s}$ \\
IRF9 & & $72^{\circ} \mathrm{C} \times 10 \mathrm{~s}$ \\
& NM_006984.2 & F: TGATACAGCTAAGACCAT & $95^{\circ} \mathrm{C} \times 3 \mathrm{~s}$ \\
STAT1 & R: CTCCTTATACTTTCCCTTAA & $56^{\circ} \mathrm{C} \times 20 \mathrm{~s}$ \\
& & $72^{\circ} \mathrm{C} \times 15 \mathrm{~s}$ \\
STAT2 & F: TATATCAAGACTGAGTTG & $95^{\circ} \mathrm{C} \times 5 \mathrm{~s}$ \\
& & R: CTATACTGTGTTCATCAT & $54^{\circ} \mathrm{C} \times 20 \mathrm{~s}$ \\
\hline
\end{tabular}

Initial activation step was at $95^{\circ} \mathrm{C}$ for $3 \mathrm{~min}$. All reactions were run with 45 cycles. 
sequences of the primers are shown in Table 1. The PCR reaction was performed using the KAPA SYBR@ Fast qPCR (Kapa Biosystems) with $1 \mu \mathrm{l}$ of cDNA in a final volume of $10 \mu \mathrm{l}$ according to the $\mathrm{Eco}^{\text {Tx }}$ Real-Time PCR system (Illumina) protocol. The efficiency of each real-time RT-PCR assay was determined before the sample amplification. Final reaction settings are shown in Table 1. Gene expression fold changes were determined using the $2^{-\Delta \Delta \mathrm{CT}}$ method with HPTR1 as housekeeping gene for normalization (Livak and Schmittgen, 2001). Data were analyzed by one-way analysis of variance (ANOVA) using Sigma Stat $3.5^{\circ}$ (Systat Software Inc) and GraphPad Prism 7.0 (GraphPad Software, Inc).

\section{Results}

\section{RSV infection}

NCI-H292 cells were inoculated with RSV (MOI 0.1) and maintained until $96 \mathrm{~h}$. The cells showed cytological alterations and distribution changes, forming clusters as early as $24 \mathrm{~h}$ after RSV infection. Such changes remained by 72 and 96 hpi. At 96 hpi, cell clusters comprised a higher cell number in respect to earlier infection times. However, we did not observe syncytia under these conditions. Viral replication was verified at $96 \mathrm{hpi}$ by detecting viral proteins using IFA and the presence of viral genome by real time RT-PCR.

\section{Genes differentially expressed during RSV infection}

To determine changes in gene expression after RSV infection (approximately $5 \log$ PFU/ml; MOI: 0.1) of NCI-H292 cells during prolonged times, the HEEBO microarray was used. Then, total RNA was isolated at 24, 48, 72 and 96 hpi and the corresponding labeled cDNA hybridized to HEEBO arrays. RNA at time 0 was also obtained. Microarray hybridization images extracted and normalized as described in Material and Methods, resulted in a global list of 16,487 probes with detectable fluorescent intensity ratios for the four time points analyzed including dye-swap replicates. The global list was subjected to an ANOVA limma test resulting in 533 significant probes $(\mathrm{p}<0.01)$ across all time points analyzed. For further analyses, for the probes that detected the same gene an average intensity per hour post-infection was calculated and only one identifier per gene was included, moreover, any repeats, unmapped ESTs and virus coding were excluded, giving rise to an end list constituted by 339 unique genes.

We performed the hierarchical clustering analysis (HCL) using the 339 differentially expressed genes at four post infection time points, including the profile obtained at time 0 (Fig. 1a). A bi-phasic gene expression profile was observed during the whole studied period. About $60 \%$ of genes were up-regulated between 24-72 hpi and then turned-off at 96 hpi. A profile of 208 down-regulated genes and 131 upregulated genes was obtained at 96 hpi as is shown in Fig. 1a. We eliminated nine designed probes with "orf" or nonprotein coding RNA. The Supplementary Table S1 shows genes and fold change $(\mathrm{Fc})$ at each time. Considering only the genes whose fold change, expressed as Fc, was between $\geq 1$ and $\leq-1$ at each hpi, we observed the same profile as in $\mathrm{HCL}$, there are mostly more up-regulated genes at 24,48 and $72 \mathrm{hpi}$ (Fig. 1b). The range of intensity was selected to analyze more relevant changes in mRNA levels. At time 0 no genes were included in the previous range. All further analyses were performed only with genes meeting that criterion of intensity $(\geq 1$ and $\leq-1)$.

\section{Changes in gene expression at different post infection times}

Common up-regulated genes and GO enrichment analysis

Overlapping up-regulated genes at each post-infection time were analyzed by Venn Diagram. Among the 330 differentially expressed genes, we did not detect common up-regulated genes when the four post-infection times were compared. However, 27 common genes were up-regulated when 24, 48 and 72 hpi were contrasted (Venn Diagram, Fig. 1c). In Table 2 are listed these 27 genes and their fold changes according to each post-infection time and considering the 24 hpi time to order Fc values from highest to lowest. Among them, IFIT1, IFI44, MX1, CXCL11 and OAS1 are the genes that presented the highest expression at earlier post infection times $(\mathrm{Fc}>3)$ and this same group had a diminished expression at $96 \mathrm{hpi}$.

The cell response against RSV triggers intracellular signaling as well as extracellular pathways to activate an antiviral state (Rusell et al., 2017). Many of the pathways of innate immune response are activated early as we also observed with the group of common up-regulated genes. Through the GO enrichment analysis, we detected four biological processes with seven or more genes belonging to each pathway, in which these 27 genes are involved, as described in Table 3. Of these common genes $51.8 \%$ (14/27) belonged to pathways of response to interferon (IFN) $\alpha$ and $\beta$. Together with these pathways, we identified that many genes that are up-regulated participate in the processes of antigen processing and presentation of exogenous peptide antigen. The activation of these four pathways during the first three days after infection suggested that this cell type responds rapidly to infection and triggers the immune response to terminate the infection. This sort of response was also found when analyzing the molecular functions, in which these genes participate. Among the detected molecular functions, two presented higher enrichment: signal transducer activity and MHC class I receptor activity (Table 3). Moreover, another three functions were detected, although with fewer genes, and these were closely 
(a)

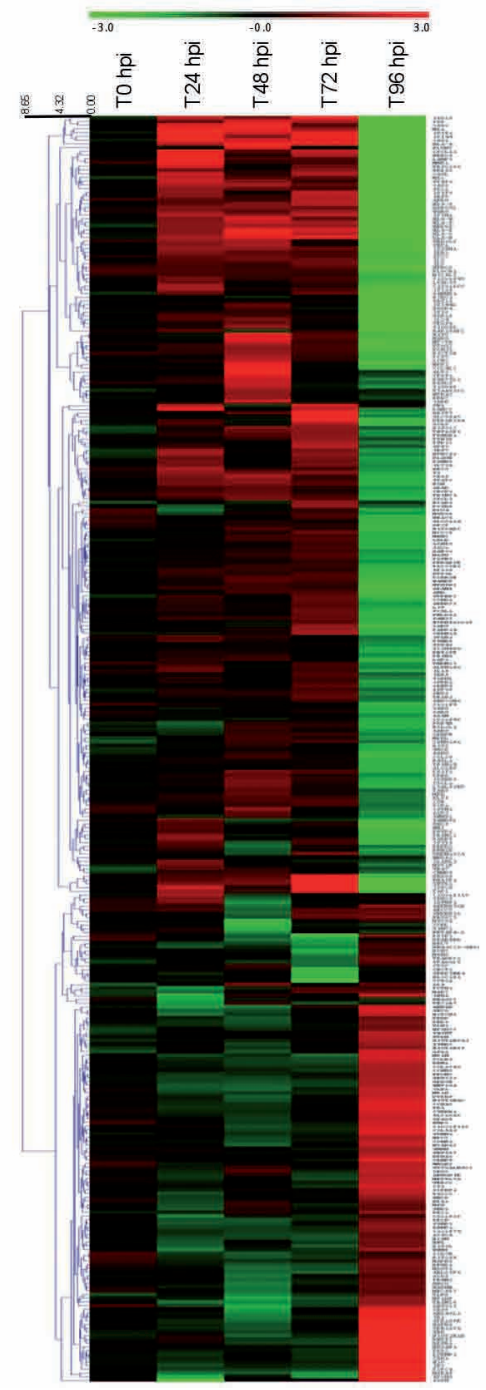

(b)

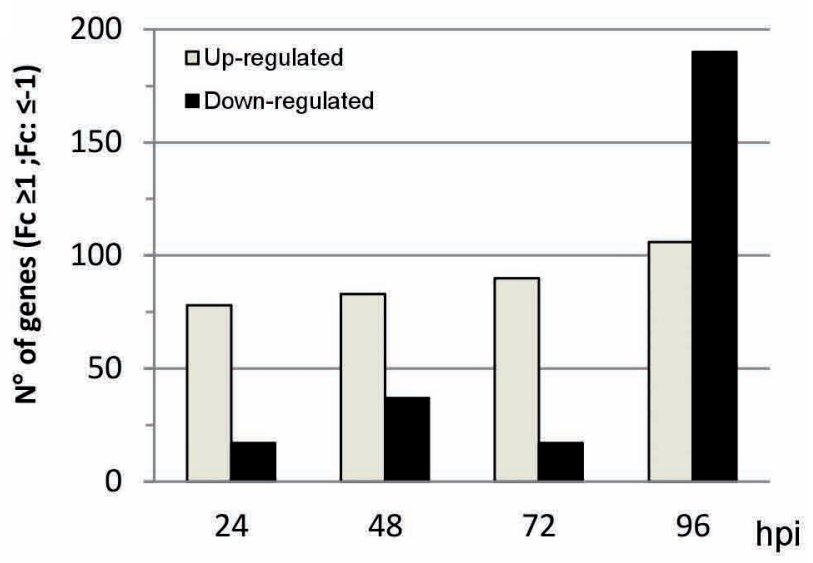

(c)

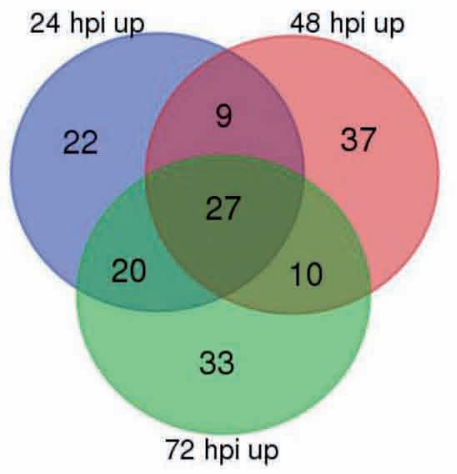

Fig. 1

Transcriptional responses induced by RSV in NCI-H292 cells

RNA from cells was extracted at 0, 24, 48, 72 and 96 hpi. Labeled cDNA was hybridized to HEEBO microarrays (MI, Microarrays Inc.). Microarray data processing is described in Materials and Methods. ANOVA test was performed, resulting in 533 significant probes $(\mathrm{p}<0.01)$ corresponding to 339 genes differentially expressed at all time points analyzed. (a)Hierarchical clustering (HCL) was performed with TMEV tool v4.7 with 339 genes using Euclidean distance measure. The color is related to the average intensities of every gene at each hpi. The red color represents the up-regulation and green the downregulation of gene expression as indicated by the scale shown on the top of the heat map. (b) Number of genes up- and down-regulated differentially $(\mathrm{p}<0.01)$ at $24,48,72$ and 96 hpi with RSV, filtered according to their intensities ( $\geq 1$ and $\leq-1)$. This analysis excluded 9 probes named as "orf" or noncoding (total 330 genes). (c) Venn diagram comparing the number of up-regulated differentially expressed genes at 24, 48 and $72 \mathrm{~h}$ after RSV infection $(\mathrm{Fc} \geq 1 \mathrm{y} \leq-1)$. There are no common genes at $96 \mathrm{hpi}$.

related to the control of viral infection: double-stranded RNA binding (dsRNA), 2'5' oligoadenylate synthetase (OAS) activity and chemokine activity (Table 3 ). It is important to note that expression of RIG-I gene, involved in one of the mechanisms of cellular defense to detect dsRNA as well as viral transcripts or genome (Liu et al., 2007) at early stages of infection, also presented significant changes $(\mathrm{p}=0.003)$. Nevertheless, it is not included in the list comprising the 27 genes because at $48 \mathrm{hpi}$ its expression was $<1$ ( Fc 0.47), while at 24 and $72 \mathrm{hpi} \mathrm{Fcs} \mathrm{were} 1.38$ and 1.54, respectively, and at $96 \mathrm{hpi}$ its expression decreased to -4.31 . The OAS genes that belong to the 2' 5 ' oligoadenylate synthetase family associated with viral RNA detection had also a strongly induced expression. Inside this family, although not included in the 27 common genes list, we found the 2'5'oligoadenylate synthetase like (OASL) gene, which presents high levels at 24 and $74 \mathrm{hpi}$ ( $\mathrm{Fc} 2.37$ and 2.15, respectively) its expression decreasing at $96 \mathrm{hpi}(\mathrm{Fc}-5.10)$. 
Table 2. Expression changes of 27 common up-regulated genes (Fc $\geq 1$; p value $<0.01$ ) between 24,48 and 72 hpi obtained according to Venn Diagram and expression changes of ISGF3 genes post infection with RSV (changes at 96 hpi are also shown)

\begin{tabular}{|c|c|c|c|c|c|}
\hline \multirow{2}{*}{ Gene symbol } & \multirow{2}{*}{ Gene name } & \multicolumn{4}{|c|}{ Fc } \\
\hline & & 24 hpi & 48 hpi & 72 hpi & 96 hpi \\
\hline IFIT1 & interferon-induced protein with tetratricopeptide repeats 1 & 6.13 & 2.54 & 2.73 & -6.42 \\
\hline IFI44 & interferon-induced protein 44 & 4.74 & 1.61 & 3.41 & -5.55 \\
\hline MX1 & myxovirus (influenza virus) resistance 1 & 4.55 & 3.36 & 1.70 & -6.31 \\
\hline CXCL11 & chemokine (C-X-C motif) ligand 11 & 3.68 & 1.08 & 2.39 & -3.82 \\
\hline OAS1 & 2'-5'-oligoadenylate synthetase $1.40 / 46 \mathrm{kDa}$ & 3.41 & 2.43 & 2.79 & -5.90 \\
\hline OAS2 & 2'-5'-oligoadenylate synthetase 2. $69 / 71 \mathrm{kDa}$ & 2.56 & 3.07 & 1.09 & -6.96 \\
\hline ISG15 & ISG15 ubiquitin-like modifier & 2.35 & 1.45 & 3.42 & -6.86 \\
\hline IFIH1 & interferon induced with helicase C domain 1 (MDA5) & 2.20 & 1.67 & 2.33 & -4.14 \\
\hline HLA-A & major histocompatibility complex. class I. A & 2.14 & 3.80 & 3.42 & -4.62 \\
\hline OAS3 & 2'-5'-oligoadenylate synthetase $3.100 \mathrm{kDa}$ & 2.11 & 1.93 & 1.27 & -4.54 \\
\hline HLA-B & major histocompatibility complex. class I. B & 1.93 & 3.66 & 3.54 & -4.57 \\
\hline IFITM1 & interferon induced transmembrane protein 1 & 1.86 & 1.78 & 1.32 & -2.86 \\
\hline F3 & Thromboplastin & 1.78 & 1.44 & 1.66 & -1.79 \\
\hline HBEGF & heparin-binding EGF-like growth factor & 1.68 & 1.95 & 1.81 & -3.87 \\
\hline HLA-C & major histocompatibility complex. class I. C & 1.68 & 3.06 & 2.16 & -3.80 \\
\hline HLA-F & major histocompatibility complex. class I. F & 1.67 & 2.25 & 1.97 & -3.48 \\
\hline HLA-E & major histocompatibility complex. class I. E & 1.63 & 2.93 & 2.62 & -3.28 \\
\hline WARS & tryptophanyl-tRNA synthetase & 1.57 & 1.14 & 1.75 & -3.93 \\
\hline HLA-H & major histocompatibility complex. class I. H (pseudogene) & 1.56 & 2.67 & 1.19 & -3.66 \\
\hline DDX60L & DEAD (Asp-Glu-Ala-Asp) box polypeptide 60-like & 1.55 & 1.64 & 1.34 & -3.61 \\
\hline B2M & beta-2-microglobulin & 1.48 & 1.59 & 1.20 & -2.15 \\
\hline ZNFX1 & zinc finger. NFX1-type containing 1 & 1.44 & 1.45 & 3.55 & -3.07 \\
\hline FST & Follistatin & 1.36 & 2.66 & 2.02 & -6.89 \\
\hline STC2 & stanniocalcin 2 & 1.33 & 1.36 & 1.01 & -2.75 \\
\hline HLA-G & major histocompatibility complex. class I. G & 1.13 & 1.54 & 2.29 & -3.29 \\
\hline IL8 & interleukin 8 & 1.13 & 1.40 & 1.31 & -3.00 \\
\hline PMAIP1 & phorbol-12-myristate-13-acetate-induced protein 1 & 1.11 & 1.40 & 3.17 & -3.17 \\
\hline \multicolumn{6}{|l|}{ ISGF3 (genes) } \\
\hline STAT1 & signal transducer and activator of transcription 1 & 2.19 & 1.68 & 0.71 & -3.58 \\
\hline STAT2 & signal transducer and activator of transcription 2 & 1.39 & 1.68 & 0.84 & -1.89 \\
\hline IRF9 & interferon regulatory factor 9 & 1.42 & 0.48 & 1.35 & -2.96 \\
\hline
\end{tabular}

The data is shown using the values of $24 \mathrm{hpi}$ from highest to lowest. hpi: hours post-infection with RSV.

Table 3. GO categories of 27 common up-regulated genes $(\mathrm{Fc} \geq 1)$ between 24,48 and 72 hpi and genes in these categories (GO enrichment analysis)

\begin{tabular}{|c|c|c|c|}
\hline & $\begin{array}{l}\text { Gene } \\
\text { count }\end{array}$ & Genes & P value \\
\hline \multicolumn{4}{|l|}{ Biological process name } \\
\hline Cellular response to cytokine stimulus & 15 & $\begin{array}{l}\text { B2M, HLA-A, HLA-B, HLA-C, HLA-E, HLA-F, HLA-G, IFIT1, IFITM1, IL8, } \\
\text { ISG15, MX1, OAS1, OAS2, OAS3 }\end{array}$ & $1.0 \mathrm{e}^{-17}$ \\
\hline Cellular response to type i interferon & 13 & $\begin{array}{l}\text { HLA-A, HLA-B, HLA-C, HLA-E, HLA-F, HLA-G, IFIT1, IFITM1, ISG15, } \\
\text { MX1, OAS1, OAS2, OAS3 }\end{array}$ & $1.6 \mathrm{e}^{-24}$ \\
\hline Cellular response to interferon-gamma & 10 & B2M, HLA-A, HLA-B, HLA-C, HLA-E, HLA-F, HLA-G, OAS1, OAS2, OAS3 & $1.4 \mathrm{e}^{-16}$ \\
\hline $\begin{array}{l}\text { Antigen processing and presentation of exogenous } \\
\text { peptide antigen via MHC-I, TAP-independent }\end{array}$ & 7 & B2M, HLA-A, HLA-B, HLA-C, HLA-E, HLA-F, HLA-G & $6.0 \mathrm{e}^{-19}$ \\
\hline \multicolumn{4}{|l|}{ Molecular function name } \\
\hline Signal transducer activity & 9 & FST, HLA-A, HLA-B, HLA-C, HLA-E, HLA-F, HLA-G, HLA-H, IFITM1 & $1.0 \mathrm{e}^{-03}$ \\
\hline MHC class I receptor activity & 7 & HLA-A, HLA-B, HLA-C, HLA-E, HLA-F, HLA-G, HLA-H & $8.5 \mathrm{e}^{-16}$ \\
\hline Double-stranded RNA binding & 4 & IFIH1, OAS1, OAS2, OAS3 & $8.5 \mathrm{e}^{-07}$ \\
\hline 2'5' oligoadenylate synthetase activity & 3 & OAS1, OAS2, OAS3 & $1.8 \mathrm{e}^{-08}$ \\
\hline Chemokine activity & 2 & CXCL11, IL8 & $2.9 \mathrm{e}^{-03}$ \\
\hline
\end{tabular}



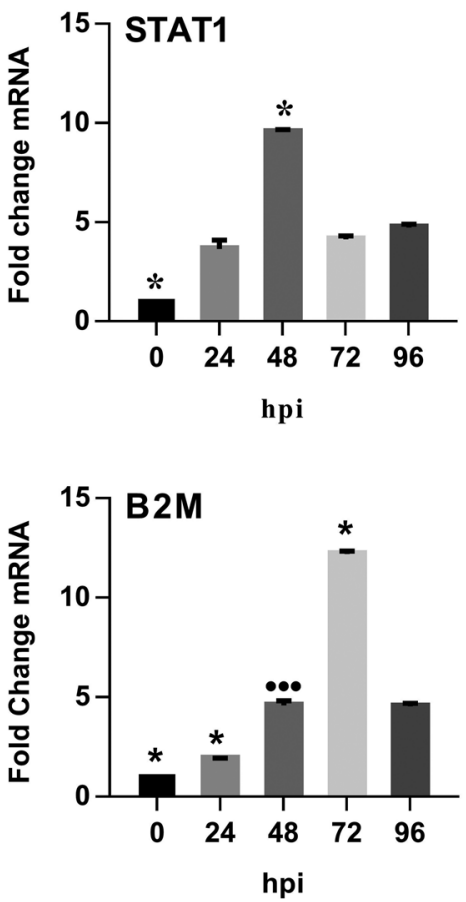
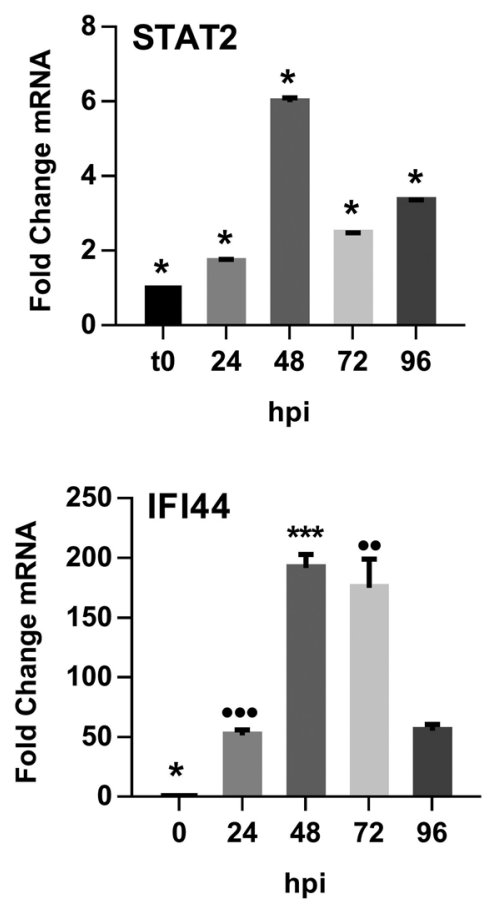

Fig. 2
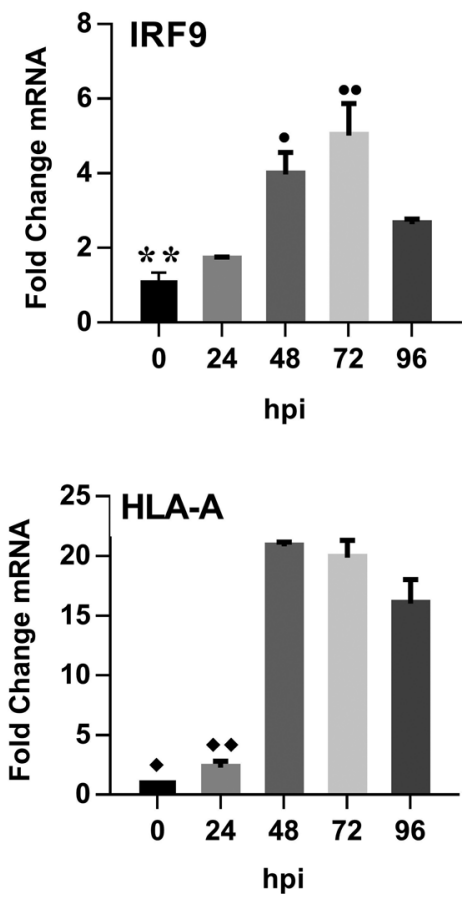

Relative gene expression of STAT1, STAT2, IRF9, B2M, IFI44 and HLA-A after RSV infection

Relative gene expression was determined by real time RT-PCR using $2^{-\Delta \Delta C T}$ method, HPTR1 was used as housekeeping gene for normalization. Each point was calculated as the mean and standard error of the mean (SEM) of four or five technical replicates. Statistical analysis (ANOVA test) was realized with

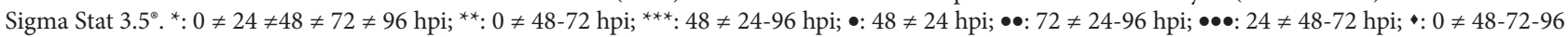
hpi; $\bullet: ~ 24 \neq 48-72-96$ hpi.

Relative quantification of ISGF3 complex and selected genes by real time RT-PCR

Taking into account that the most enriched pathways were associated to IFN $\alpha / \beta$ response, we verified in our infection model whether one of the factors activated by IFN, the transcription factor IFN-stimulated gene factor 3 (ISGF3), was up-regulated. This complex is composed of STAT1, STAT2 and IRF9 (McNab et al., 2015). The microarray analysis showed that these three genes were up-regulated at 24,48 and $72 \mathrm{hpi}$ and down-regulated at $96 \mathrm{hpi}$ as shown in Table 2. This difference was significant $(\mathrm{p}<0.001)$, however because their Fc values were lower than 1 at some experimental time points, they are not included in the list of common genes. We performed real time RT-PCR analysis to obtain a relative quantification of expression of these genes; we detected significant changes after infection as observed in Fig. 2. All these genes presented a peak of expression between 48 and $72 \mathrm{hpi}$. We also analyzed the expression of 3 common genes: B2M, IFI44 and HLA-A (Table 2), detecting significant changes in their expression ( $\mathrm{p}<0.05)$. IFI44 and HLA-A had an increased expression between 48 and 72 hpi (Fig. 2). Just as it was for ISGF3 genes, we did not detect a significant decrease in expression of these genes as we observed in microarrays at $96 \mathrm{hpi}$.
Unique up-regulated genes and GO enrichment analysis

As shown in the Venn Diagram, we detected unique upregulated genes at 24, 48 and 72 hpi (Fig. 1c). In Table 4 are shown the main GO biological processes, in which these genes are involved and the number of genes detected in each process. The top 10 up-regulated genes are listed in Table 5, depicting the fold changes at each post infection time, including $96 \mathrm{hpi}$.

At 24 hpi, we found 78 genes having an expression $\geq 1$ and 22 of them (28.2\%) were only overexpressed at 24 hpi (Fig.1b and c). MMP1 gene had the highest expression in this group (Table 5) and its protein product corresponds to a metalloproteinase that participates in processes of extracellular matrix remodeling (Parks et al., 2004; Ala-aho and Kähäri, 2005). These 22 genes are mainly associated with immune system processes based on the GO enrichment analysis (Table 4). Thus, the greatest proportion of genes $(\mathrm{n}=13)$ was detected in the GO category "defense response" where we found IFI35, IFIT5, IL1A, IL1RL1, ITGB1, MST1R, NMI, PARP9, PLSCR1, PSMB8, TRIM22, UBA7 and USP18. Among them, IFI35, PARP9, TRIM22 and IL1RL1 presented the highest activation as shown in Table 5.

At $48 \mathrm{hpi}$, we detected 83 genes with an expression $\geq 1$ and 37 of them were up-regulated only at $48 \mathrm{hpi}$ (Fig. $1 \mathrm{~b}$ and c). 
The ALX3 gene, a transcriptional regulator (Perez-Villamilet al., 2004), presented the highest activation (Table 5). Considering the GO enrichment pathways, in which these 37 genes are included, apart from the immune response pathways, it is worthy to note that genes that participate in apoptotic processes were up-regulated (Table 4). Genes belonging to the immune system process were ADAR, AQP3, BPIFA1, CXCL1, DUSP4, EIF2AK2, IFI44L, LCN2, OSTM1, RICTOR, S100A8, S100A9, TCF7 and VEGFA. The genes that presented the top activation in this process were BPIFA1 (Fc 2.70) and S100A9 (Fc 2.27). On the other hand, genes detected under the label "regulation of apoptotic process" were ADAR, ALX3, HTRA2, IGFBP3, LCN2, PTGS2, S100A8, S100A9, TCF7 and VEGFA, where ALX3, S100A9, LCN2 and TCF7 showed the greatest fold changes of 4.08, 2.27, 2.17 and 2.10, respectively.

At $72 \mathrm{hpi}$, we detected 90 genes presenting the expression $\geq 1$, among them $33(36.7 \%)$ are up-regulated only at this time. The highest expression was found in SLC30A7 and PPP1R15A, as shown in Table 5. The gene SLC30A7 is associated with a cation transmembrane transporter activity and transport to the Golgi (Kirschke and Huang, 2003), while PPP1R15A or GADD34 codes for a protein that responds to genomic damage activating apoptosis (Yagi et al., 2003). The main pathways encompassing the 33 genes are listed in Table 4. Among them stand out both response to endogenous stimulus and response to hormone stimulus. In this last process were found the genes CDKN1A, PCSK9, FOSL1, CCND1, TXNIP, TRIB3, ABCC8, LDLR, AHR. Both CDKN1A and PCSK9 presented the top activations with FC values of 2.02 and 1.85, respectively. CDKN1A (known as $\mathrm{P} 21 / \mathrm{WAF}$ ) codes for a potent cyclin-dependent kinase inhibitor promoting cell cycle arrest in response to a variety of stimuli (Karimianet al., 2016) and PCSK9 belongs to the convertase family, family of proteases that process protein and peptide precursors trafficking through the secretory pathway (Seidah and Prat, 2012).

At $96 \mathrm{hpi}$, we found 122 up-regulated genes out of 330 (37.5\%), among them 106 presented changes $\geq 1$. As mentioned before, we did not detect any genes co-upregulated with all other pi times. We detected one common gene with 48 hpi (GLA) and four genes with 72 hpi (ANKRD36, ABCC8, PRSS23 and MAP2). No common genes were present when compared to $24 \mathrm{hpi}$. Top ten genes having the highest expression are listed in Table 5, and all of them presented changes $>3$. The ATOH8 gene is on the top of the list at $96 \mathrm{hpi}$ and codes for a transcription factor involved in differentiation processes (Chen et al, 2011). The main biological processes, in which these 106 genes participate, are shown in Table 4. Unlike the up- regulated pathways at previous pi times, at 96 hpi there is activation of cell processes related to cell cycle and cytoskeleton rearrangement. This probably accounts for cell processes associated with cellular restructuring caused by the viral infection, such as
Table 4. GO categories of up-regulated $(\mathrm{Fc} \geq 1)$ and down-regulated (Fc $\leq-1)$ unique genes obtained at 24, 48, 72 and 96 hpi after Venn Diagram analysis

\begin{tabular}{|c|c|c|}
\hline GO: Biological process name & Gene count & $P$ value \\
\hline \multicolumn{3}{|l|}{ Up-regulated } \\
\hline \multicolumn{3}{|l|}{24 hpi (n: 22 genes) } \\
\hline Defense response & 13 & $5.8 \mathrm{e}^{-08}$ \\
\hline Response to cytokine stimulus & 9 & $1.4 \mathrm{e}^{-06}$ \\
\hline Innate immune response & 9 & $1.9 \mathrm{e}^{-06}$ \\
\hline Cytokine-mediated signaling pathway & 7 & $2.0 \mathrm{e}^{-05}$ \\
\hline \multicolumn{3}{|l|}{48 hpi (n: 37 genes) } \\
\hline Inmune system process & 14 & $1.6 \mathrm{e}^{-03}$ \\
\hline Defense response & 12 & $1.0 \mathrm{e}^{-03}$ \\
\hline Regulation of apoptotic process & 10 & $5.0 \mathrm{e}^{-03}$ \\
\hline $\begin{array}{l}\text { Leucocyte migration involved in inflam- } \\
\text { matory response }\end{array}$ & 2 & $5.0 \mathrm{e}^{-03}$ \\
\hline \multicolumn{3}{|l|}{72 hpi (n: 33 genes) } \\
\hline Response to hormone stimulus & 9 & $2.1 \mathrm{e}^{-03}$ \\
\hline Response to lipid & 8 & $2.1 \mathrm{e}^{-03}$ \\
\hline Response to organic nitrogen & 8 & $2.1 \mathrm{e}^{-03}$ \\
\hline \multicolumn{3}{|l|}{96 hpi (n: 106 genes) } \\
\hline Cell cycle phase & 21 & $1.6 \mathrm{e}^{-05}$ \\
\hline Mitotic cell cycle & 19 & $3.1 \mathrm{e}^{-05}$ \\
\hline Mitosis & 13 & $4.8 \mathrm{e}^{-05}$ \\
\hline Microtubule cytoskeleton organization & 12 & $2.7 \mathrm{e}^{-05}$ \\
\hline \multicolumn{3}{|l|}{ Down-regulated } \\
\hline \multicolumn{3}{|l|}{24 hpi (n: 17 genes) } \\
\hline Nervous system development & 9 & $2.3 \mathrm{e}^{-05}$ \\
\hline \multicolumn{3}{|l|}{48 hpi (n: 37 genes) } \\
\hline Response to organic nitrogen & 5 & $1.4 \mathrm{e}^{-02}$ \\
\hline Response to molecule of bacterial origin & 3 & $1.7 \mathrm{e}^{-02}$ \\
\hline Regulation of interleukin- 8 production & 2 & $3.2 \mathrm{e}^{-03}$ \\
\hline \multicolumn{3}{|l|}{72 hpi (n: 17 genes) } \\
\hline RNA processing & 3 & $1.8 \mathrm{e}^{-02}$ \\
\hline Golgi vesicle transport & 2 & $1.1 \mathrm{e}^{-02}$ \\
\hline \multicolumn{3}{|l|}{96 hpi (n: 189 genes) } \\
\hline Innate immune response & 55 & $3.1 \mathrm{e}^{-36}$ \\
\hline Response to virus & 43 & $4.6 \mathrm{e}^{-37}$ \\
\hline Response to type i interferon & 26 & $4.8 \mathrm{e}^{-32}$ \\
\hline
\end{tabular}

$\mathrm{n}$ : number of genes submitted to GO enrichment analysis $(\mathrm{p}<0.05)$.

the syncytia formation. The genes that presented the highest changes under the process "mitotic cell cycle" were TOP2A, UBD, NUSAP1, TPX2, CDK1 and ASPM (Supplementary Table S1). On the other hand, in the process "microtubule cytoskeleton organization" we detected, apart from NUSAP1, TPX2 and CDK1, the genes STMN1, CKS2, UBE2C, SPAG5, ZWINT, CCNB1, TACC2 and with lower change PRC1 and MAP2 (Supplementary Table S1).

Genes down-regulated at every single post infection time

In the group of down-regulated genes, we did not detect any common genes that keep a diminished expression pattern 
Table 5. Expression changes of unique genes (top ten, up and down-regulated) obtained per time after RSV infection according to Venn Diagram analysis $(\mathrm{Fc}: \geq 1, \leq-1)$

\begin{tabular}{|c|c|c|c|c|c|c|c|}
\hline \multicolumn{2}{|c|}{ 24hpi } & \multicolumn{2}{|c|}{48 hpi } & \multicolumn{2}{|c|}{72 hpi } & \multicolumn{2}{|c|}{96 hpi } \\
\hline Gene symbol & Fc & Gene symbol & Fc & Gene symbol & Fc & Gene symbol & Fc \\
\hline \multicolumn{8}{|c|}{ Up-regulated genes } \\
\hline MMP1 & 3.38 & ALX3 & 4.08 & SLC30A7 & 3.08 & ATOH8 & 4.18 \\
\hline REC8 & 2.08 & CCL4L2 & 3.66 & PPP1R15A & 3.02 & TOP2A & 3.93 \\
\hline IFI35 & 1.93 & MTX1 & 3.12 & ATF3 & 2.24 & GPR109A & 3.62 \\
\hline PARP9 & 1.73 & CPSF1 & 2.77 & CDKN1A & 2.02 & PHTF2 & 3.58 \\
\hline TRIM22 & 1.60 & PLUNC & 2.70 & TFPI2 & 2.00 & $\mathrm{UBD}$ & 3.53 \\
\hline $\mathrm{CDH} 23$ & 1.56 & ISPD & 2.33 & SOX9 & 2.00 & HIST1H1B & 3.51 \\
\hline IGFBP1 & 1.54 & RAB3IL1 & 2.32 & PCSK9 & 1.85 & MXRA5 & 3.44 \\
\hline IL1RL1 & 1.49 & EGFL8 & 2.31 & PARP14 & 1.84 & NUSAP1 & 3.39 \\
\hline SAMD9L & 1.47 & S100A9 & 2.27 & TXNIP & 1.76 & ID3 & 3.21 \\
\hline MST1R & 1.42 & LCN2 & 2.17 & CARS & 1.74 & TPX2 & 3.20 \\
\hline \multicolumn{8}{|c|}{ Down-regulated genes } \\
\hline ASPM & -4.26 & OCRL & -2.50 & ССТ6А & -3.11 & PLUNC & -5.69 \\
\hline INHA & -2.11 & MYO9A & -2.37 & BLOC1S1 & -2.46 & STC1 & -5.39 \\
\hline DNAJC2 & -1.86 & UIMC1 & -2.16 & CNOT1 & -2.46 & RAP1GAP2 & -5.28 \\
\hline TBC1D7 & -1.72 & ZNF823 & -1.87 & SERPINB4 & -2.36 & OASL & -5.11 \\
\hline TCTN1 & -1.65 & MT1DP & -1.86 & $\mathrm{RCN} 2$ & -2.04 & MX2 & -4.57 \\
\hline NNMT & -1.46 & CD59 & -1.77 & RPL7 & -1.71 & GDF15 & -4.37 \\
\hline ETV4 & -1.29 & IGFBP1 & -1.65 & DNAJC25 & -1.50 & RIG-I & -4.31 \\
\hline NOTCH3 & -1.29 & KRTAP4-6 & -1.59 & MSH6 & -1.50 & IFI44L & -4.17 \\
\hline MAP2 & -1.20 & ANXA8L1 & -1.55 & STAG3L3 & -1.25 & PRIC285 & -4.12 \\
\hline SNCG & -1.16 & TLR9 & -1.54 & CTSC & -1.23 & DUSP4 & -4.01 \\
\hline
\end{tabular}

among the 4 post infection times, and only the MXRA5 gene was inhibited at 24,48 and $76 \mathrm{hpi}$ (Fc-1.32, $-1.00,-1.58$, respectively). Nevertheless, at $96 \mathrm{hpi}$ this same gene was up-regulated (Fc 3.44). MXRA5 codes for a protein related to extracellular matrix remodeling (Walker and Volkmuth, 2002).

At $24 \mathrm{hpi}$, we detected 131 genes out of 330 that were inhibited (40\%), with only 17 genes that presented Fc $<-1$. TRIM29 and AHNAK genes were down-regulated at both 24 (Fc -1.29 and -1.64 , respectively) and $48 \mathrm{hpi}$ (Fc -1.57 and -1.41 , respectively). ATOH8 gene was common between 24 and 72 hpi (Fc -2.03 and -1.75 , respectively), being one of the genes showing the highest inhibition at $24 \mathrm{hpi}$. Top ten genes down-regulated only at $24 \mathrm{hpi}$ are shown in Table 5. Due to the low number of genes with $\mathrm{Fc}<-1$, the main pathway detected in the GO enrichment analysis was associated with genes belonging to the nervous system development family (Table 4), comprised of nine genes: AHNAK, ANK3, ASPM, ATOH8, ETV4, INHA, MAP2, NOTCH3 and TCTN1. Among them, ASPM, a gene associated with mitotic spindle regulation, presented the highest inhibition (Table 5) (Higgins et al., 2010).

At 48 hpi, 131 genes (39.7\%) were down-regulated, 37 of them presented an expression $\leq-1$. The genes having the greatest changes are shown in Table 5. OCRL gene presented the highest inhibition, and has been described in several processes such as regulating membrane trafficking and primary cilium formation (Madhivanan et al., 2015). When these 37 genes were analyzed, there were only a few biological processes enriched. As shown in Table 4, the main biological process is linked to the response to organic nitrogen with the genes included: ABCC8, IGFBP1, MGST1, PTPRF, and TLR9.

At 72 hpi, we detected 118 down-regulated genes that corresponded to $35.8 \%$ of total genes with significant changes in expression after infection. Only 17 of them exhibited changes lower than -1. PSIP1 presented the highest decrease in expression (Fc-3.38). This gene associates with the function "RNA polymerase II" and is also inhibited at $48 \mathrm{hpi}$ (Fc -1.04) (Singh et al., 2001). As shown in Table 5, we detected that CCT6A is the gene that presented the highest decrease of expression; the protein coded by this gene has a chaperone role and assists the folding of proteins, especially actin and tubulin (Mukherjee et al., 2010). In the GO enrichment analysis, only two biological processes were enriched: RNA processing and Golgi vesicle transport, although with a few genes belonging to each one: CNOT1, PSIP1 and RPL7 to the first pathway (Fc in Table 5) and TRAPPC1 (Fc-1.21) and BLOC1S1 (FC-2.46) to the second. 
At $96 \mathrm{hpi}$, we found a higher percentage of down-regulated genes compared to all other times after infection analyzed. The genes up-regulated between 24-72 hpi were turned off at 96 hpi. Thus 208 out of 330 differentially expressed genes showed a reduced expression and 189 of them had Fc $\leq-1$. The genes with highest changes are shown in Table 5, but we excluded OAS2, FST, IGS15, IFIT1, MX1, OAS1 and IFI44, because these genes were included in the Table 2 (common genes). In addition, 189 genes were associated with a biological process related to immune response by the GO enrichment analysis (Table 4), showing a control of the antiviral mechanism attenuating several other pathways. In GO category "response to virus", we detected 43 of 189 genes (22.8\%). Among them 8 genes belonged uniquely to this pathway and were not included in the other two categories (Venn Diagram analysis). These genes were IFI44, IFI44L, IL6, EIF2AK2, TRIM22, FOSL1, GBP3, and TRIM5 (Fc are in Supplementary Table S1).

\section{Discussion}

The respiratory syncytial virus is the main etiologic agent of lower respiratory tract infections in infants. In Chile, in a study on healthy term infants younger than 6 months with acute LRTI, $59.7 \%$ of patients presented an infection due to RSV and 22.6\% a co-infection (Luchsinger et al., 2014). Most symptomatic cases consult 2 to 3 days after the symptoms have started and for this reason, in vitro models that cover greater infection timing can contribute to a better understanding of virus pathogenesis.

Our aim was to analyze temporal changes in cellular gene expression after infection by RSV using the human cell line derived from lung, NCI-H292, that is a continuous human lung muco-epidermoid cell line permissive to infection by RSV and other human paramyxoviruses. We analyzed expression changes at 4 times after infection, namely 24, 48, 72 and $96 \mathrm{~h}$ at a low multipilicity of infection, $5 \mathrm{Log} \mathrm{PFU} / \mathrm{ml}$, approximately $0.1 \mathrm{MOI}$. This $\log \mathrm{PFU} / \mathrm{ml}$ value is similar to those reported in the literature in nasal samples of RSV infants. In the study performed by ElSaleeby et al. the mean nasal viral load was of $4.63 \mathrm{log} \mathrm{PFU} / \mathrm{ml}$ in children under 1 year old on the first day of enrollment (ElSaleeby et al., 2011). Similar RSV load values have been previously obtained by DeVicenzo. In this study, RSV-A load was of $4.77 \log$ PFU/ml in nasal wash in a hospitalized infant upon enrollment. The $y$-intercept of the regression line for RSV-A was of 5.27, suggesting that this viral load would be at the onset of symptoms (Day 0) (DeVincenzo, 2004). In a follow-up study of hospitalized RSV-infants younger than 1 year old, they also detected similar viral loads, approximately $6 \log \mathrm{PFU} / \mathrm{ml}$ at the time of admission (Brint et al., 2017). This background indicates that the inoculum used in our study measured as $\log \mathrm{PFU} / \mathrm{ml}$ is comparable to in vivo situations, when we consider hospitalized infants, a risk group, whose dynamics of infection is important to understand. Although the MOI used represents a low density of infection when expressed in terms of number of cells, we have no possibility of extrapolating it to in vivo values. Despite this low MOI, we confirmed the presence of RSV by IFA and real time RT-PCR; nevertheless we were not able to observe syncytia formation, just cell clusters. Previus data have shown that NCI-H292 cell line presents a delayed cytopathic effect when compared to the cell lines HeLa-I and HEp-2 after RSV infection. NCI-H292 cell line showed a lower number of isolations (52\%) but it presented a better cell stability (Periniet al., 2007). This cell line has also been used as a model for inflammation induction by several agents that affect lungs, with similar response as the primary lung epithelial cells (Newland and Richter, 2008). Thus, NCI-H292 cell line could be a viable model for studying the effects of RSV infection on gene expression at longer infection times.

Previous studies of gene expression after RSV infection in different cell models using microarrays have been reported. A lower airway epithelial cell A549, type II alveolar cells and a single post infection time have been used in several studies (Zhang et al., 2001, 2003; Tian et al., 2002). Only in the study of Martinez et al, they carried out a follow up of $3 \mathrm{hpi}$ at 6,12 and $24 \mathrm{~h}$ with an inoculum of RSV of $3 \mathrm{PFU}$, close to that used in our study (Martínez et al., 2007). Other studies have used human bronchial epithelial cell BEAS-2B; in the work by Huang et al. they performed the analysis at 4 and $24 \mathrm{hpi}$, while Mayer et al. only at $4 \mathrm{hpi}$, both used MOI of 1 (Mayer et al., 2007; Huang et al., 2008).On the other hand, Janssen used an animal model. They inoculated BALBc/mice and analyzed the expression profile in lung tissue at 1 and 3 days post infection (Jannsen et al., 2007).

Therefore, most of the published studies do not perform a follow up of the cellular response after RSV infection and with our study is only comparable what happens at $24 \mathrm{hpi}$. In addition, variations on the type of microarrays used and MOI may result in differences between our results and those obtained by other groups of researchers.

In our study, we identified 330 differentially expressed genes at 4 post infection times with RSV by microarray. We obtained different expression patterns, a bi-phasic gene expression profile, with a predominantly down-regulated profile at 96 hpi compared to earlier hpi. This pattern is maintained when considering the genes with changes $\geq 1$ or $\leq-1$. About $60 \%$ of the genes were up-regulated between 24-72 hpi. This early gene expression pattern showed a rapid and sustained activation of several genes after RSV infection and then turned off at $96 \mathrm{hpi}$. This change is possibly due to the viral replication and cellular anti-viral response. A previous report by Martinez indicates an early activation at 6 hours post infection (Martínez et al., 2007). It is known that specific 
viral proteins such as NS1 and NS2 can interact with cellular pathways to block the anti-viral effect of the cell (Barik, 2013; Schmidt and Varga, 2017). Although in our study we did not evaluate the presence of these viral proteins, unpublished results from our group with an infection at MOI of 1 in this cell line have revealed that the maximum viral replication is reached at $96 \mathrm{hpi}$. This could indicate a possible involvement of RSV replication in counteracting the anti-viral response of the cell by decreasing the expression of innate immune response genes as we observed at $96 \mathrm{hpi}$.

Between 24-72 hpi, we detected an up-regulated gene expression pattern. Twenty-seven genes remained up-regulated (Fc $\geq 1$ ) at 24, 48 and 72 hpi. These genes are mainly related to innate immune response, highlighting the activation of dsRNA sensors, IFN producing pathways, IFN- stimulated pathways, and pathways associated to antigen presentation. Viral infection is first detected by sensors such as RLRs, which include RIG-I and IFIH1 (MDA5) (Goubau et al., 2013). In our study, the levels of IFIH1 detected were higher than RIG-I although the temporality was similar, both presenting a decrease at 96 hpi. Other reports have suggested that the main activated pathway after RSV infection is RIG-I. Liu and colleagues found binding of viral RNA only to RIG-I and not to IFIH1 (Liu et al., 2007). These apparent divergences can be explained given the different cell lines and MOI that were used. However, in murine lung tissue a great activation of IFIH1 is detected at $24 \mathrm{hpi}$ and remains up-regulated at 3 days post infection (Janssen et al., 2007). RSV has generated mechanisms to counteract RIG-I and IFIH1 action. The RSV NS2 protein is able to interact with RIG-I, blocking its action (Ling et al., 2009), while in infected HEp 2 cells at 12 hpi, IFIH1, MAVS and the viral protein $\mathrm{N}$ were co-localized in inclusion bodies, the primary site for viral RNA replication (Lifland et al., 2012). Sequestering of IFIH1 could diminish IFN expression. Facing these virus adaptation mechanisms, the cell probably induces a sustained activation of IFIH1 and RIG-I expression during the $72 \mathrm{hpi}$, as we observed in our cell model.

The pathways of viral infection recognition through IRF3 and IRF7 activate the expression of type I IFNs (IFN $\alpha$ and $\beta$ ) and ISGs that trigger inflammation signals and chemoattraction of immune response cells in order to control the infection (Takaoka and Yanai, 2006). Although we did not detect changes in the expression of IRF3 and IRF7, neither we detected IFN $\alpha$ and IFN $\beta$ mRNAs, we did detect genes of pathways that respond to these signals. One of them, widely described by its antiviral action, is the transcription complex IGSF3 that translocates to the nucleus and binds to different promoters that respond to interferon (ISRE) (Fink and Grandvaux, 2013; McNab et al., 2015). We detected a significant increase of STAT1, STAT2 and IRF9 mRNA levels that comprise this complex, from 24 until $72 \mathrm{hpi}$. Although via real time RT-PCR we did not find an abrupt decrease in expression at $96 \mathrm{hpi}$ as the one detected by microarrays, we indeed observed a decrease in mRNA levels at $96 \mathrm{hpi}$. This could be due to technical differences regarding the amount of mRNA used in each technique and the amplification region selected in real time RT-PCR, as in microarray assay several probes target each mRNA. STAT1 expression was the highest compared to the other two genes. In studies using STAT1 KO mice, there has been observed an increased susceptibility to infections with different bacteria and viruses, including ssRNA negative virus like vesicular stomatitis virus (VSV), however, there are no reports about RSV infection (Boisson-Dupuis et al., 2012). It is well established that ISGF3 responds to IFN $\alpha$ and $\beta$ stimuli so we suggested in our cell model of RSV infection that the virus is able to activate the IFN pathway as observed in other studies. In the study by Jannsen and colleagues using a murine model, they also detected up-regulation of STAT1 and STAT2 genes at days 1 and 3 after infection, STAT1 being the one with the highest activation (Janssen et al., 2007). In infants with LTRI caused by influenza or RSV infection, STAT1 and STAT2 activation is detected systemically (Mejías et al., 2013). RSV proteins NS1 and NS2 can affect the formation of ISGF3 by sequestering STAT2 and resulting in its degradation (Lo et al., 2005; Swedan et al., 2009, 2011). RSV is able to suppress the both the IFN production pathway and the IFN effector pathway. This could explain the pattern of different expression between 24-72 hpi and $96 \mathrm{hpi}$.

It is known that there are many genes whose expression is dependent on IFN, triggered downstream of the IFN receptor. Among the 27 up-regulated common genes, several belong to these signaling pathways. IFIT1 (ISG56) is one of the genes with highest response to IFN. The Fc was the highest among the common genes at $24 \mathrm{hpi}$. It has also been detected in the murine model, showing one of the major changes on day 1 post infection (Janssen et al., 2007). IFIT1 acts by sensing viral RNA (Fensterl and Sen, 2015). Among the mechanisms of anti-viral action of IFIT1 has been described an inhibitory action on the initiation of translation by its interaction with eIF3 (Fensterl and Sen, 2011). It is also able to recognize 5-mRNA ends, whose caps lack 2'O-methylation of the first ribose, competing with eIF4E to block the translation of viral mRNAs bearing those features. IFIT1 also binds and sequesters 5' triphosphorylated RNAs that are at the 5 ' ends of genomic and non-genomic RNA of some RNA viruses altering the viral replication. A study by Barik determined that 5 ' terminal cap structure of RSV mRNA is the cap 0 type and has no 2'-O methylation on the first ribose (Barik, 1993). This structure might be the target for IFIT1 and its expression activation would be an important antiviral mechanism. In studies using coronavirus lacking the 2' O-methyl transferase activity, a higher susceptibility to the IFIT1 action controlling the infection has been observed (Diamond, 2014; Menachery et al., 2014). It is unknown 
whether RSV has some counteracting mechanism for the lack of 2'-O-methylation in its mRNAs, although RSV protects its genomic RNA through the binding of viral protein $\mathrm{N}$, which it covers completely, creating an RNase-resistant nucleocapsid (Collins et al., 2013).

Identification of foreign RNAs is an antiviral response also performed by enzymes that are activated by dsRNA and belong to the family of ISGs (Kristiansen et al., 2011). In our experiments we detected an increase in expression of oligoadenylate synthetases(OAS1, OAS2 and OAS3). This increase was higher at 24 hpi for OAS1, although it remained increased until $72 \mathrm{hpi}$. Similar, in the infant study there is an increased expression of OAS1 and to a lesser extent of OAS2.This last study was performed between 24 to 72 hours after admission into the hospital (Mejías et al., 2013). In addition, both in the murine model and A549 cells infected with RSV, an increase in mOasla and OAS2 has also been detected at 24 hpi (Janssen et al., 2007; Martínez et al., 2007). These enzymes synthesize 2'-5' oligoadenylates activating a latent RNase, RNase L, to induce RNA degradation, resulting in the inhibition of viral replication. On the other hand, in this family we find OASL. This protein, unlike OASs, has no enzymatic activity so its mechanism of antiviral action remains elusive. OASL contains two tandem ubiquitin-like domains (UBL) at the C-terminus and this domain is absent in OASs. We detected increased OASL expression at 24 and 72 hpi and it decreased at 96 hpi. It has been proposed that OASL could bind to the pUb site of RIG-I, thereby increasing the sensitivity to detect RNAs (Zhu et al., 2015). The involvement of OASL and particularly the importance of UBL domain in the response against RSV has been demonstrated using HEK293 cells with constant expression of OASL (Dhar et al., 2015). In the whole blood microarrays study on infants, the activation of OASL was detected following RSV infection in a higher proportion than the other genes of the family (Mejias et al., 2013). These results suggest an important participation of this pathway in the early control of infection.

In the common genes group we also detected an important up-regulation of IFI44, a gene induced by IFN $\alpha$ and $\beta$. In murine lung tissue infected with RSV, a strong activation was obtained at $24 \mathrm{hpi}$, diminishing at day three (Janssen et al., 2007). Both Fjaerli and Mejías detected an increased expression of IFI44 at a systemic level in infants hospitalized due to RSV infection (Fjaerliet al., 2006; Mejías et al., 2013). The role of this strong up-regulation and its involvement in the control of the infection is not known; only in the model of HIV infection it has been demonstrated that IFI44 inhibited viral replication (Power et al., 2015).

Other group of strongly up-regulated genes corresponds to HLA, associated to antigen recognition. $\mathrm{CD}^{+}$cytotoxic $\mathrm{T}$ lymphocytes recognize the antigens presented by class I HLA molecules, the activation of these immune cells al- lows the control of infection but they also participate in the generation of lung damage after RSV infection. Class i HLA molecules correspond to a heterodimer that includes B2M that appeared differentially expressed in our study. In the report of Guo et al. (2015) in A549 cells with MOI similar to ours they did not detect significant changes of HLA-A, HLA-B or HLA-C at 36 hpi. However, when using a MOI of 0.3 or 1.0 they detected changes in gene expression and cell surface protein expression. In this model, they propose a modulation of HLAs expression through the activation of NLRC5 via RIG-I/IFN $\beta$ (Guo et al., 2015). Previous studies have already demonstrated the important role of IFN $\beta$ in modulating that expression (Garofalo et al, 1996). An increase of HLA-B and E has also been observed in A459 cells at 24 hpi (Martínez et al., 2007). In our model, we detected higher activation of $\mathrm{HLA}-\mathrm{A} / \mathrm{B} / \mathrm{C} / \mathrm{E} / \mathrm{F} / \mathrm{H}$ expression at $48 \mathrm{hpi}$ of RIG-I. Considering the involvement of these molecules in antigen presentation, such activation was expected; however, we are not able to explain what is the biological consequence of activation of several HLA. On the other hand, B2M expression has been used as a reference gene (Radonić et al., 2004), but our data show significant changes in its expression at all hpi analyzed. Accordingly, when performing relative expression studies in viral infection models, it is necessary to consider that the antigen presentation pathway, where $\mathrm{B} 2 \mathrm{M}$ is involved, is strongly regulated and this gene does not have a stable expression to be used as a reference gene.

One of the consequences of infection is the inflammatory response activation. In our study, we detected one of the highest up-regulations the up-regulation of CXCL11, and to a lesser extent IL8. Both in A549 cells and murine lung tissue detect activation as well of CXCL11 expression mainly at 24 hpi (Janssen et al., 2007; Martínez et al., 2007). It is known that epithelial cells release recruitment mediators of immune cells to the infection site; although CXCL11 belongs to the chemokines family, the direct effect of CXCL11 on RSV infection is unknown (Farrag and Almajhdi, 2016). On the other hand, in our model, IL8 expression, one of the most important mediators of the inflammatory response, had a slight increase over time; however, it has been observed that there is a significant production of this neutrophil chemoattractant at a systemic level and in the respiratory tract (Farrag and Almajhji, 2016; Rusell et al., 2017). In infants younger than 6 months infected with RSV, an increased amount of IL8 has been detected at a systemic level. In addition, this chemokine is present in higher concentrations in RSVinfants with severe LTRI compared with controls or RSVinfants with moderate disease (Larrañaga et al., 2009). The difference between the expression obtained in our cell line and the systemic levels might be due to the fact that many other cells, especially the immune system cells, are able to release this chemokine during infection and its expression is not restricted to the epithelial cells. 
When analyzing the pathways, in which the individual genes were activated at each time after infection, we observed mainly an activation of the immune response pathway at 24 and $48 \mathrm{hpi}$. However, at $48 \mathrm{hpi}$ is also present the activation of genes that modulate apoptosis. At $72 \mathrm{hpi}$, we detected genes associated with response to several stimuli such as hormones, lipids and organic nitrogen. At $96 \mathrm{hpi}$, we also detected a second expression pattern; over 120 genes, which remained silenced until $72 \mathrm{hpi}$, were steeply up-regulated by 96 hpi. A great proportion of these genes was related to cell cycle, mitosis and microtubules rearrangement. Upregulation of these genes was expected considering the morphological changes that cells experience after infection and the clustering we observed, all changes that should require signals for cytoskeleton rearrangement. It is known that the virus must need the cell cytoskeleton to allow assembly of viral proteins and genome and liberation from host cells (budding), therefore, knowing that in our cell model, there is a greater viral replication associated with greater viral particles release between 72 and $96 \mathrm{hpi}$, it is highly possible that the virus modulates the signals in order to be released (Shahriari et al., 2016).

Although we detected up-regulated genes at $96 \mathrm{hpi}$, the expression pattern at that time was mainly down-regulated. These genes were associated with the innate immune response, including genes associated with virus response and IFN type I response. Among these genes are included several of the common genes activated at 24, 48 and $72 \mathrm{hpi}$ as shown in Table 2. OAS2 and ISG15 were the genes that presented the strongest down-regulation. As we previously mentioned, OAS2 is associated with the recognition pathway of viral RNAs to induce their degradation. The virus responds against the cell antiviral response using several mechanisms. One of them is related to sequestering of cellular proteins by viral proteins, interfering with different pathways of the innate immune response (Wu et al., 2012; Schmidt and Varga, 2017). It has been observed that RSV NS1 sequesters IRF3, interfering with its transcriptional activity associated with IFN and possibly reflects a decrease in the expression of genes associated with that pathway (Ren et al., 2011). Considering that a peak of viral replication is observed in NCI-H292 cells at 96 hpi when using a MOI of 1 (personal communication), the greatest amount of viral proteins such as NS1 at this time may block the ISGs expression. This could support the highest proportion of down-regulated genes detected at 96 hpi.

ISG15 is the second most down-regulated gene at $96 \mathrm{hpi}$. This gene codes for an ubiquitin-like protein that modifies other proteins. Several proteins are ISGylated in the response to interferon during viral infection, altering their function (Morales and Lenschow, 2013; Zhao et al., 2013). ISG15 ${ }^{-/-}$KO mice are more susceptible to infection by Sendai virus and influenza a and B virus. Nevertheless, ISG15's antiviral action would not associate with the inhibition of viral replication but with protein ISGylation (Morales et al., 2015).This last mechanism has also been described in the RSV infection of A549 cells and A549 ISG15 ${ }^{-1-}$.The antiviral effect of ISG15 would be evident in cells having a high amount of ISG15 before virus infection, namely those cells stimulated by interferon released by the infected cells (González-Sanz et al., 2016). In a murine lung epithelial cells model (MLE-15), an increase of ISG15 after RSV infection is observed, this increment is higher when the infection is performed using RSV without the $G$ protein $(\Delta G)$, suggesting a control of $G$ protein over ISG15 expression (Moore et al., 2008). ISG15 appears to be an important mediator of the antiviral response of RSV as well other viral infections (Zhao et al., 2013).

Using NCI-H292 cellular model of infection, we detected many up-regulated genes between 24 to 72 hpi. Among them, 27 genes remain are highly up-regulated, suggesting an important participation in the control of viral infection. It has been mainly described that the proteins coded by these genes participate in the innate immune response pathways associated with the activation of IFN $\alpha$ and $\beta$ and ISGs. Many of them have been detected increased in circulation of RSV infants. Other pathways are up-regulated more extensively at each post infection time, such as the regulation of apoptotic processes at $48 \mathrm{hpi}$ and mitotic processes and organization of the cytoskeleton at $96 \mathrm{hpi}$; they could be related to the changes that RSV induces at the cellular level during its replication. Although we did not perform quantification of the viral load, studies carried out by us and others have determined interference of the RSV proteins with the cellular antiviral response; these interactions possibly affect the transcription of cellular genes involved in that response. Our cellular model will allow us to carry out future studies by analyzing cellular pathways that have relevance in the elimination of the virus at later times after infection, as well as studying specific pathways that are differentially expressed in RSV-infected infants showing a different infection severity.

Acknowledgments. This work was funded by the Research Project Fondecyt $\mathrm{N}^{\circ} 11070254$ granted to S.A. by the Office of Science and Technology Development of the Chilean Government. We want to thank Dr. Pedro Piedra (Baylor College of Medicine, Houston, TX, US) for kindly providing RSV/A/Tracy via Dr. Luis Avendaño, Virology Program, Institute of Biomedical Sciences, Faculty of Medicine, University of Chile.

Supplementary information is available in the online version of the paper.

\section{References}

Ala-aho R, Kähäri VM (2005): Collagenases in cancer. Biochimie 87, 273-286. https://doi.org/10.1016/j.biochi.2004.12.009 
Ampuero S, Luchsinger V, Tapia L, Palomino MA, Larrañaga CE (2011): SP-A1, SP-A2 and SP-D gene polymorphisms in severe acute respiratory syncytial infection in Chilean infants. Infect. Genet. Evol. 11, 1368-1377. https://doi. org/10.1016/j.meegid.2011.04.033

Avendaño LF, Palomino MA, Larrañaga C (2003): Surveillance for respiratory syncytial virus in infants hospitalized for acute lower respiratory infection in Chile (1989 to 2000). J. Clin. Microbiol. 41, 4879-4882. https://doi.org/10.1128/ LCM.41.10.4879-4882.2003

Barik S (1993): The structure of the 5 terminal cap of the respiratory syncytial virus mRNA. J. Gen. Virol. 74, 485-490. https:// doi.org/10.1099/0022-1317-74-3-485

Barik S (2013): Respiratory syncytial virus mechanisms to interfere with type 1 interferons. Curr. Top. Microbiol. Immunol. 372, 173-191.

Boisson-Dupuis S, Kong XF, Okada S, Cypowyj S, Puel A, Abel L, Casanova JL (2012): Inborn errors of human STAT1: allelic heterogeneity governs the diversity of immunologi$\mathrm{cal}$ and infectious phenotypes. Curr. Opin. Immunol. 24, 364-378. https://doi.org/10.1016/j.coi.2012.04.011

Brint ME, Hughes JM, Shah A, Miller CR, Harrison LG, Meals EA, Blanch J, Thompson CR, Cormier SA, DeVincenzo JP (2017): Prolonged viral replication and longitudinal viral dynamic differences among respiratory syncytial virus infected infants.Pediatr Res. 82, 872-880. https:// doi.org/10.1038/pr.2017.173

Chen M, Hu KF, Rozell B, Orvell C, Morein B, Liljeström P (2002): Vaccination with recombinant alphavirus or immune-stimulating complex antigen against respiratory syncytial virus. J. Immunol. 169, 3208-3216. https://doi. org/10.4049/jimmunol.169.6.3208

Chen J, Dai F, Balakrishnan-Renuka A, Leese F, Schempp W, Schaller F, Hoffmann MM, Morosan-Puopolo G, Yusuf F, Bisschoff IJ, Chankiewitz V, Xue J, Chen J, Ying K, Brand-Saberi B (2011): Diversification and molecular evolution of ATOH8, a gene encoding a bHLH transcription factor. PLoS One 6, e23005. https://doi.org/10.1371/ journal.pone.0023005

Collins PL, Fearns R, Graham BS (2013): Respiratory syncytial virus: virology, reverse genetics, and pathogenesis of disease. Curr. Top. Microbiol. Immunol. 372, 3-38. https:// doi.org/10.1007/978-3-642-38919-1 1

Collins PL, Melero JA (2011): Progress in understanding and controlling respiratory syncytial virus: still crazy after all these years. Virus Res. 162, 80-99. https://doi.org/10.1016/j. virusres.2011.09.020

DeVincenzo JP (2004): Natural infection of infants with respiratory syncytial virus subgroups A and B: a study of frequency, disease severity, and viral load. Pediatr. Res. 56, 914-917. https://doi.org/10.1203/01.PDR.0000145255.86117.6A

Dhar J, Cuevas RA, Goswami R, Zhu J, Sarkar SN, Barik S (2015): 2'-5'-Oligoadenylate synthetase-like protein inhibits respiratory syncytial virus replication and is targeted by the viral nonstructural protein 1. J. Virol. 89, 10115-10119. https://doi.org/10.1128/JVI.01076-15

Diamond MS (2014): IFIT1: A dual sensor and effector molecule that detects non-2'-O methylated viral RNA and inhibits its translation. Cytokine Growth Factor Rev. 25, 543-550. https://doi.org/10.1016/j.cytogfr.2014.05.002

El Saleeby CM, Bush AJ, Harrison LM, Aitken JA, DeVincenzo JP (2011): Respiratory syncytial virus load, viral dynamics, and disease severity in previously healthy naturally infected children. J. Infect. Dis. 204, 996-1002. https:// doi.org/10.1093/infdis/jir494

Farrag MA, Almajhdi FN (2016): Human respiratory syncytial virus: role of innate immunity in clearance and disease progression. Viral Immunol. 29, 11-26. https://doi. org/10.1089/vim.2015.0098

Fensterl V, Sen GC (2011): The ISG56/IFIT1 gene family. J. Interferon Cytokine Res. 31, 71-78. https://doi.org/10.1089/ jir.2010.0101

Fensterl V, Sen GC (2015): Interferon-induced IFIT proteins: their role in viral pathogenesis. J. Virol. 89, 2462-2468. https:// doi.org/10.1128/JVI.02744-14

Fink K, Grandvaux N (2013): STAT2 and IRF9: Beyond ISGF3. JAKSTAT 2, e27521. https://doi.org/10.4161/jkst.27521

Fjaerli HO, Bukholm G, Krog A, Skjaeret C, Holden M, Nakstad B (2006): Whole blood gene expression in infants with respiratory syncytial virus bronchiolitis. BMC Infect. Dis. 6, 175. https://doi.org/10.1186/1471-2334-6-175

Garofalo R, Mei F, Espejo R, Ye G, Haeberle H, Baron S, Ogra PL, Reyes VE (1996): Respiratory syncytial virus infection of human respiratory epithelial cells up-regulates class I MHC expression through the induction of IFN-beta and IL-1 alpha. J. Immunol. 157, 2506-2513.

González-Sanz R, Mata M, Bermejo-Martín J, Álvarez A, Cortijo J, Melero JA, Martínez I (2016): ISG15 is upregulated in respiratory syncytial virus infection and reduces virus growth through protein ISGylation. J. Virol. 90, 3428-3438. https://doi.org/10.1128/JVI.02695-15

Goubau D, Deddouche S, Reise Sousa C (2013): Cytosolic sensing of viruses. Immunity 38, 855-869. https://doi.org/10.1016/j. immuni.2013.05.007

Griffiths C, Drews SJ, Marchant DJ (2017): Respiratory syncytial virus: infection, detection, and new options for prevention and treatment. Clin. Microbiol. Rev. 30, 277-319. https:// doi.org/10.1128/CMR.00010-16

Guo X, Liu T, Shi H, Wang J, Ji P, Wang H, Hou Y, Tan RX, Li E (2015): Respiratory syncytial virus infection upregulates NLRC5 and major histocompatibility complex class i expression through RIG-I induction in airway epithelial cells. J. Virol. 89, 7636-7645. https://doi.org/10.1128/JVI.00349-15

Higgins J, Midgley C, Bergh AM, Bell SM, Askham JM, Roberts E, Binns RK, Sharif SM, Bennett C, Glover DM, Woods CG, Morrison EE, Bond J (2010): Human ASPM participates in spindle organisation, spindle orientation and cytokinesis. BMC Cell. Biol. 11, 85-101. https://doi. org/10.1186/1471-2121-11-85

Huang YC, Li Z, Hyseni X, Schmitt M, Devlin RB, Karoly ED, Soukup JM (2008): Identification of gene biomarkers for respiratory syncytial virus infection in a bronchial epithelial cell line. Genomic Med. 2, 113-125. https:// doi.org/10.1007/s11568-009-9080-y

Janssen R, Pennings J, Hodemaekers H, Buisman A, van Oosten M, de Rond L, Öztürk K, Dormans J, Kimman T, Hoebee B 
(2007): Host transcription profiles upon primary respiratory syncytial virus infection. J. Virol. 81, 5958-5967. https://doi.org/10.1128/JVI.02220-06

Karimian A, Ahmadi Y, Yousefi B (2016): Multiple functions of p21 in cell cycle, apoptosis and transcriptional regulation after DNA damage. DNA Repair (Amst) 42, 63-71. https://doi. org/10.1016/j.dnarep.2016.04.008

Kim TH, Lee HK (2014): Innate immune recognition of respiratory syncytial virus infection. BMB Rep. 47, 184-191. https:// doi.org/10.5483/BMBRep.2014.47.4.050

Kirschke CP, Huang L (2003): ZnT7, a novel mammalian zinc transporter, accumulates zinc in the Golgi apparatus. J. Biol. Chem. 278, 4096-4102. https://doi.org/10.1074/ jbc.M207644200

Kristiansen H, Gad HH, Eskildsen-Larsen S, Despres P, Hartmann $\mathrm{R}$ (2011): The oligoadenylate synthetase family: an ancient protein family with multiple antiviral activities. J. Interferon Cytokine Res. 31, 41-47. https://doi.org/10.1089/ jir.2010.0107

Larrañaga C, Ampuero S, Luchsinger V, Carrión F, Aguilar N, Morales P, Palomino MA, Tapia L, Avendaño LF (2009): Impaired immune response in severe human lower tract respiratory infection by respiratory syncytial virus. Pediatr. Infect. Dis. J. 28, 867-873. https://doi.org/10.1097/ INF.0b013e3181a3ea71

Lifland AW, Jung J, Alonas E, Zurla C, Crowe JE, Santangelo PJ (2012): Human respiratory syncytial virus nucleoprotein and inclusion bodies antagonize the innate immune response mediated by MDA5 and MAVS. J. Virol. 86, 8245-8258. https://doi.org/10.1128/JVI.00215-12

Ling Z, Tran KC, Teng MN (2009): Human respiratory syncytial virus nonstructural protein NS2 antagonizes the activation of beta interferon transcription by interacting with RIG-I. J. Virol. 83, 3734-3742. https://doi.org/10.1128/ JVI.02434-08

Liu P, Jamaluddin M, Li K, Garofalo RP, Casola A, Brasier AR (2007): Retinoic acid-inducible gene i mediates early antiviral response and toll-like receptor 3 expression in respiratory syncytial virus-infected airway epithelial cells. J. Virol. 81, 1401-1411. https://doi.org/10.1128/ IVI.01740-06

Livak KJ, Schmittgen TD (2001): Analysis of relative gene expression data using real-time quantitative PCR and the 2- $\Delta \Delta$ CT method. Methods 25, 402-408. https://doi. org/10.1006/meth.2001.1262

Lo MS, Brazas RM, Holtzman MJ (2005): Respiratory syncytial virus nonstructural proteins NS1 and NS2 mediate inhibition of Stat2 expression and alpha/beta interferon responsiveness. J. Virol. 79, 9315-9319. https://doi.org/10.1128/ JVI.79.14.9315-9319.2005

Luchsinger V, Ampuero S, Palomino MA, Chnaiderman J, Levican J, Gaggero A, Larrañaga CE (2014): Comparison of virological profiles of respiratory syncytial virus and rhinovirus in acute lower tract respiratory infections in very young Chilean infants, according to their clinical outcome. J. Clin. Virol. 61, 138-144. https://doi.org/10.1016/j. jev.2014.06.004
Luchsinger V, Piedra PA, Ruiz M, Zunino E, Martínez MA, Machado C, Fasce R, Ulloa MT, Fink MC, Lara P, Avendaño LF (2012): Role of neutralizing antibodies in adults with community-acquired pneumonia by respiratory syncytial virus. Clin Infect Dis. 54, 905-912. https://doi. org/10.1093/cid/cir955

Madhivanan K, Ramadesikan S, Aguilar RC (2015): Role of Ocrl1 in primary cilia assembly. Int. Rev. Cell. Mol. Biol. 317, 331-347. https://doi.org/10.1016/bs.ircmb.2015.02.003

Martínez I, Lombardía L, García-Barreno B, Domínguez O, Melero JA (2007): Distinct gene subsets are induced at different time points after human respiratory syncytial virus infection of A549 cells. J. Gen. Virol. 88, 570-581. https://doi. org/10.1099/vir.0.82187-0

Mayer AK, Muehmer M, Mages J, Gueinzius K, Hess C, Heeg K, Bals R, Lang R,Dalpke AH (2007): Differential recognition of TLR-dependent microbial ligands in human bronchial epithelial cells. J. Immunol. 178, 3134-3142 https://doi. org/10.4049/jimmunol.178.5.3134

McNab F, Mayer-Barber K, Sher A, Wack A, O'Garra A (2015): Type I interferons in infectious disease. Nat. Rev. Immunol. 15, 87-103. https://doi.org/10.1038/nri3787

Mejias A, Dimo B, Suarez NM, Garcia C, Suarez-Arrabal MC, Jartti T, Blankenship D, Jordan-Villegas A, Ardura MI, Xu Z, Banchereau J, Chaussabel D, Ramilo O (2013): Whole blood gene expression profiles to assess pathogenesis and disease severity in infants with respiratory syncytial virus infection. PLoS Med. 10, e1001549. https://doi. org/10.1371/journal.pmed.1001549

Menachery VD, Yount BL Jr, Josset L, Gralinski LE, Scobey T, Agnihothram S, Katze MG, Baric RS (2014): Attenuation and restoration of severe acute respiratory syndrome coronavirus mutant lacking 2'-o-methyltransferase activity. J. Virol. 88, 4251-4264. https://doi.org/10.1128/JVI.03571-13

Moore EC, Barber J, Tripp RA (2008): Respiratory syncytial virus (RSV) attachment and nonstructural proteins modify the type $\mathrm{i}$ interferon response associated with suppressor of cytokine signaling (SOCS) proteins and IFNstimulated gene-15 (ISG15). Virol. J. 5, 116-126. https:// doi.org/10.1186/1743-422X-5-116

Morales DJ, Lenschow DJ (2013): The antiviral activities of ISG15. J. Mol. Biol. 425, 4995-5008. https://doi.org/10.1016/j. imb.2013.09.041

Morales DJ, Monte K, Sun L, Struckhoff JJ, Agapov E, Holtzman MJ, Stappenbeck TS, Lenschow DJ (2015): Novel mode of ISG15-mediated protection against influenza a virus and Sendai virus in mice. J. Virol. 89, 337-349. https:// doi.org/10.1128/JVI.02110-14

Mukherjee K, Conway de Macario E, Macario AJ, Brocchieri L (2010): Chaperonin genes on the rise: new divergent classes and intense duplication in human and other vertebrate genomes. BMC Evol Biol. 10, 64-83. https://doi. org/10.1186/1471-2148-10-64

Mukherjee S, Lukacs NW (2013): Innate immune responses to respiratory syncytial virus infection. Curr. Top. Microbiol. Immunol. 372,139-154. https://doi.org/10.1007/978-3$\underline{642-38919-1 \quad 7}$ 
Newland N, Richter A (2008): Agents associated with lung inflammation induce similar responses in NCI-H292 lung epithelial cells. Toxicol. In Vitro 22, 1782-1788. https:// doi.org/10.1016/j.tiv.2008.07.009

Parks WC, Wilson CL, López-Boado YS (2004): Matrix metalloproteinases as modulators of inflammation and innate immunity. Nat. Rev. Immunol. 4, 617-629. https://doi. org/10.1038/nri1418

Pérez-Villamil B, Mirasierra M, Vallejo M (2004): The homeoprotein Alx3 contains discrete functional domains and exhibits cell-specific and selective monomeric binding and transactivation. J. Biol. Chem. 279, 38062-38071. https://doi.org/10.1074/jbc.M400800200

Perini AP, Barbosa ML, Botosso VF, de Moraes CT, Gillio AE, Hens N, Stewien KE, Durigon EL (2007): Comparison of HeLa-I, HEp-2 and NCI-H292 cell lines for the isolation of human respiratory syncytial virus (HRSV). J. Virol. Methods 146, 368-371. https://doi.org/10.1016/j. jviromet.2007.07.004

Power D, Santoso N, Dieringer M, Yu J, Huang H, Simpson S, Seth I, Miao H, Zhu J (2015): IFI44 suppresses HIV-1 LTR promoter activity and facilitates its latency. Virology 481, 142-150. https://doi.org/10.1016/j.virol.2015.02.046

Radonić A, Thulke S, Mackay IM, Landt O, Siegert W, Nitsche A (2004): Guideline to reference gene selection for quantitative real-time PCR. Biochem. Biophys. Res. Commun. 313, 856-862. https://doi.org/10.1016/j. bbrc.2003.11.177

Ren J, Liu T, Pang L, Li K, Garofalo RP, Casola A, Bao X (2011): A novel mechanism for the inhibition of interferon regulatory factor-3-dependent gene expression by human respiratory syncytial virus NS1 protein. J. Gen. Virol. 92, 2153-2159. https://doi.org/10.1099/vir.0.032987-0

Russell CD, Stefan A, Unger SA, Walton M, Schwarze J (2017): The human immune response to respiratory syncytial virus infection. Clin. Microbiol. Rev. 30, 481-502. https://doi. org/10.1128/CMR.00090-16

Schmidt ME, Varga SM (2017): Modulation of the host immune response by respiratory syncytial virus proteins. J. Microbiol. 55, 161-171. https://doi.org/10.1007/s12275-017-7045-8

Seidah NG, Prat A (2012): The biology and therapeutic targeting of the proprote in convertases. Nat. Rev. Drug Discov. 11, 367-383. https://doi.org/10.1038/nrd3699

Shahriari S, Gordon J, Ghildyal R (2016): Host cytoskeleton in respiratory syncytial virus assembly and budding. Virol. J. 13, 161-171. https://doi.org/10.1186/s12985-016-0618-Z

Singh DP, Fatma N, Kimura A, Chylack LT, Shinohara T (2001): LEDGF binds to heat shock and stress-related element to activate the expression of stress-related genes. Biochem. Biophys. Res. Commun. 283, 943-955. https://doi. org/10.1006/bbrc.2001.4887

Swedan S, Andrews J, Majumdar T, Musiyenko A, Barik S (2011): Multiple functional domains and complexes of the two nonstructural proteins of human respiratory syncytial virus contribute to interferon suppression and cellular location. J. Virol. 85, 10090-10100. https://doi.org/10.1128/ IVI.00413-11
Swedan S, Musiyenko A, Barik S (2009): Respiratory syncytial virus nonstructural proteins decrease levels of multiple members of the cellular interferon pathways. J. Virol. 83, 9682-9693. https://doi.org/10.1128/JVI.00715-09

Takaoka A, Yanai H (2006): Interferon signalling network in innate defence. Cell. Microbiol. 8, 907-922. https://doi. org/10.1111/j.1462-5822.2006.00716.x

Tian B, Zhang Y, Luxon BA, Garofalo RP, Casola A, Sinha M, Brasier AR (2002): Identification of NF- $\kappa B$-dependent gene networks in respiratory syncytial virus-infected cells. J. Virol. 76, 6800-6814. https://doi.org/10.1128/ IVI.76.13.6800-6814.2002

Tregoning JS, Schwarze J (2010): Respiratory viral infections in infants: causes, clinical symptoms, virology, and immunology. Clin. Microbiol. Rev. 23, 74-98. https://doi. org/10.1128/CMR.00032-09

Turner T, Kopp B, Paul G, Landgrave L, Hayes D, Thompson R (2014): Respiratory syncytial virus: current and emerging treatment options. Clinicoecon. Outcomes Res. 6, 217-225. https://doi.org/10.2147/CEOR.S60710

Walker MG, Volkmuth W (2002): Cell adhesion and matrix remodeling genes identified by co-expression analysis. Gene Funct. Dis. 3, 109-112. https://doi.org/10.1002/ gnfd. 200290000

Welliver TP, Reed JL, Welliver RC (2008): Respiratory syncytial virus and influenza virus infections: observations from tissues of fatal infant cases. Pediatr. Infect. Dis. J. 27, S92S96. https://doi.org/10.1097/INF.0b013e318168b706

Wu W, Tran KC, Teng MN, Heesom KJ, Matthews DA, Barr JN, Hiscox JA (2012): The interactome of the human respiratory syncytial virus NS1 protein highlights multiple effects on host cell biology. J. Virol. 86, 7777-7789. https://doi. org/10.1128/JVI.00460-12

Yagi A, Hasegawa Y, Xiao H, Haneda M, Kojima E, Nishikimi A, Hasegawa T, Shimokata K, Isobe K (2003): GADD34 induces $\mathrm{p} 53$ phosphorylation and $\mathrm{p} 21 / \mathrm{WAF} 1$ transcription. J. Cell. Biochem. 90, 1242-1249. https://doi.org/10.1002/ jcb. 10711

Zhang Y, Jamaluddin M, Wang S, Tian B, Garofalo RP, Casola A, Brasier AR (2003): Ribavirin treatment up-regulates antiviral gene expression via the interferon-stimulated response element in respiratory syncytial virus-infected epithelial cells. J. Virol. 77, 5933-5947. https://doi. org/10.1128/JVI.77.10.5933-5947.2003

Zhang Y, Luxon BA, Casola A, Garofalo RP, Jamaluddin M, Brasier AR (2001): Expression of respiratory syncytial virus-induced chemokine gene networks in lower airway epithelial cells revealed by cDNA microarrays. J. Virol. 75, 9044-9058. https://doi.org/10.1128/JVI.75.19.90449058.2001

Zhao C, Collins MN, Hsiang TY, Krug RM (2013): Interferoninduced ISG15 pathway: an ongoing virus-host battle. Trends Microbiol. 21, 181-186. https://doi.org/10.1016/j. tim.2013.01.005

Zhu J, Ghosh A, Sarkar SN (2015): OASL-a new player in controlling antiviral innate immunity. Curr. Opin. Virol. 12, 15-19. https://doi.org/10.1016/j.coviro.2015.01.010 


\title{
Supplementary information
}

\section{Time-course of transcriptome response to respiratory syncytial virus infection in lung epithelium cells}

\author{
S. AMPUERO ${ }^{1}$, R. ANDAUR ${ }^{1}$, M. MILANO ${ }^{1}$, M. MORENO$^{2}$, L. LIZAMA ${ }^{1}$, C. LARRAÑAGA ${ }^{1}$, U. URZÚA ${ }^{3}$
}

${ }^{1}$ Virology Program, Institute of Biomedical Sciences, Faculty of Medicine, University of Chile; Postal address 8380453, Independencia 1027, Independencia, Santiago, Chile; ${ }^{2}$ Laboratory of Oncology and Molecular Genetics, Coloproctology Unit, Clinica Las Condes, Santiago, Chile; Postal address 7591046, Santiago, Chile; ${ }^{3}$ Department of Basic and Clinical Oncology, Faculty of Medicine, University of Chile, Postal adress 8380453, Santiago, Chile

Received December 27, 2017; revised February 2, 2018; accepted July 12, 2018

Supplementary Table S1. List of 330 differentially expressed genes after RSV infection ( $p$ value $<0.01$ )

\begin{tabular}{|c|c|c|c|c|c|c|}
\hline \multirow{2}{*}{ Gene symbol } & \multirow{2}{*}{ Gene name } & \multicolumn{5}{|c|}{ Fc } \\
\hline & & 0 hpi & 24 hpi & 48 hpi & 72 hpi & 96 hpi \\
\hline AARS & alanyl-tRNA synthetase & -0.39 & $-0,61$ & 0,73 & 0,40 & $-1,77$ \\
\hline АВCC8 & ATP-binding cassette, sub-family C (CFTR/MRP), member 8 & 0.68 & 0,95 & $-1,09$ & 1,13 & 1,16 \\
\hline ACACA & acetyl-CoA carboxylase alpha & 0.16 & $-0,59$ & $-0,84$ & $-0,88$ & 1,23 \\
\hline ADAM8 & ADAM metallopeptidase domain 8 & -0.13 & 0,76 & 0,80 & 0,67 & $-2,81$ \\
\hline ADAR & adenosine deaminase, RNA-specific & 0.29 & 0,91 & 1,17 & 0,55 & $-1,67$ \\
\hline AHNAK & AHNAK nucleoprotein & -0.37 & $-1,64$ & $-1,42$ & 0,61 & 2,51 \\
\hline AHR & aryl hydrocarbon receptor & -0.05 & $-0,21$ & 0,91 & 1,01 & $-2,85$ \\
\hline ALDH1A3 & aldehyde dehydrogenase 1 family, member A3 & 0.28 & 1,11 & $-0,21$ & 0,95 & $-1,51$ \\
\hline ALX3 & ALX homeobox 3 & 0.17 & $-0,02$ & 4,08 & 0,15 & $-0,54$ \\
\hline ANK3 & ankyrin 3, node of Ranvier & -0.06 & $-1,00$ & 0,53 & $-0,29$ & 1,21 \\
\hline ANKRD36 & Ankyrin repeat domain 36 & 0.26 & 0,32 & $-1,24$ & 1,13 & 1,31 \\
\hline ANKRD36B & ankyrin repeat domain $36 \mathrm{~B}$ & 0.59 & 0,64 & $-1,30$ & 0,21 & 1,66 \\
\hline ANXA8L1 & annexin A8-like 1 & -0.10 & $-0,30$ & $-1,55$ & $-0,12$ & 2,82 \\
\hline AQP3 & aquaporin 3 (Gill blood group) & 0.65 & $-0,10$ & 1,19 & 0,00 & $-1,60$ \\
\hline AREG & amphiregulin & 0.77 & 1,14 & 0,81 & 2,13 & $-3,37$ \\
\hline ARHGDIB & Rho GDP dissociation inhibitor (GDI) beta & 0.16 & $-0,62$ & 0,62 & $-0,72$ & 2,03 \\
\hline ARL6IP5 & ADP-ribosylation-like factor 6 interacting protein 5 & 0.06 & $-0,10$ & $-1,14$ & $-1,11$ & 1,38 \\
\hline ARRDC3 & arrestin domain containing 3 & 0.20 & 0,61 & 0,37 & 1,18 & $-1,69$ \\
\hline ASAM & adipocyte-specific adhesion molecule & 0.46 & $-0,27$ & 0,08 & 0,19 & $-1,57$ \\
\hline ASNS & asparagine synthetase (glutamine-hydrolyzing) & -0.49 & $-0,05$ & 0,67 & 0,25 & $-2,62$ \\
\hline ASPM & asp (abnormal spindle) homolog, microcephaly associated (Drosophila) & 0.25 & $-4,26$ & 0,18 & $-0,06$ & 3,14 \\
\hline ATF3 & activating transcription factor 3 & -0.23 & 0,74 & 0,04 & 2,24 & $-0,90$ \\
\hline ATOH8 & atonal homolog 8 (Drosophila) & -0.20 & $-2,03$ & $-0,26$ & $-1,72$ & 4,18 \\
\hline B2M & Beta-2-microglobulin & 0.02 & 1,48 & 1,59 & 1,20 & $-2,15$ \\
\hline BCAM & basal cell adhesion molecule (Lutheran blood group) & -0.11 & $-0,83$ & $-0,69$ & $-0,93$ & 1,39 \\
\hline BCAR3 & breast cancer anti-estrogen resistance 3 & -0.83 & $-0,05$ & $-0,48$ & 1,74 & $-0,53$ \\
\hline BCL2L1 & BCL2-like 1 & -0.29 & $-0,94$ & 0,76 & 0,66 & $-2,11$ \\
\hline BIRC3 & baculoviral IAP repeat-containing 3 & 0.18 & $-0,16$ & $-0,48$ & $-0,03$ & $-3,32$ \\
\hline BLOC1S1 & biogenesis of lysosomal organelles complex-1, subunit 1 & 0.03 & $-0,23$ & $-0,15$ & $-2,46$ & 0,09 \\
\hline
\end{tabular}




\begin{tabular}{|c|c|c|c|c|c|c|}
\hline \multirow{2}{*}{ Gene symbol } & \multirow{2}{*}{ Gene name } & \multicolumn{5}{|c|}{ Fc } \\
\hline & & 0 hpi & 24 hpi & 48 hpi & 72 hpi & 96 hpi \\
\hline BTN2A1 & Butyrophilin, subfamily 2 , member A1 & -0.55 & 1,97 & 0,14 & 1,73 & $-1,48$ \\
\hline CARS & cysteinyl-tRNA synthetase & 0.20 & $-0,06$ & $-0,30$ & 1,74 & $-2,69$ \\
\hline CCL20 & chemokine (C-C motif) ligand 20 & -0.22 & 0,30 & 0,93 & 0,32 & $-2,36$ \\
\hline CCL4L2 & chemokine (C-C motif) ligand 4-like 2 & 0.38 & 0,48 & 3,66 & $-0,18$ & $-2,37$ \\
\hline CCNA2 & cyclin A2 & 0.16 & $-0,50$ & $-0,59$ & $-0,14$ & 2,55 \\
\hline CCNB1 & cyclin B1 & -0.25 & $-0,26$ & $-0,87$ & $-0,35$ & 2,24 \\
\hline CCNB2 & cyclin B2 & -0.05 & $-0,23$ & $-0,40$ & $-0,65$ & 2,03 \\
\hline CCND1 & cyclin D1 & -0.12 & 0,71 & 0,13 & 1,27 & $-2,05$ \\
\hline ССТ6А & chaperonin containing TCP1, subunit $6 \mathrm{~A}$ (zeta 1$)$ & -0.04 & $-0,28$ & 0,07 & $-3,11$ & 0,07 \\
\hline CD55 & $\begin{array}{l}\text { CD55 molecule, decay accelerating factor for complement (Cromer blood } \\
\text { group) }\end{array}$ & 0.46 & 1,53 & 2,04 & 0,80 & $-2,17$ \\
\hline CD59 & CD59 molecule, complement regulatory protein & -0.04 & 0,13 & $-1,78$ & 0,04 & 2,80 \\
\hline CDCP1 & CUB domain containing protein 1 & 0.33 & 0,90 & 1,27 & 0,49 & $-1,76$ \\
\hline $\mathrm{CDH} 23$ & cadherin-related 23 & 0.51 & 1,56 & $-1,07$ & 0,02 & 0,50 \\
\hline CDK1 & cyclin-dependent kinase 1 & -0.22 & $-0,44$ & 0,02 & $-0,59$ & 3,19 \\
\hline CDKN1A & cyclin-dependent kinase inhibitor 1A (p21, Cip1) & -0.40 & $-0,29$ & 0,44 & 2,02 & $-2,08$ \\
\hline CEBPB & CCAAT/enhancer binding protein (C/EBP), beta & 0.02 & $-0,48$ & 0,77 & 0,77 & $-1,52$ \\
\hline CEBPG & CCAAT/enhancer binding protein $(\mathrm{C} / \mathrm{EBP})$, gamma & 0.29 & 0,23 & $-0,04$ & 1,23 & $-1,74$ \\
\hline CENPF & centromere protein $\mathrm{F}$ & 0.42 & $-0,02$ & 0,00 & $-0,33$ & 2,66 \\
\hline CFB & complement factor B & 0.26 & 0,49 & 1,00 & 1,06 & $-1,39$ \\
\hline CFI & complement factor I & 0.08 & $-0,25$ & $-0,01$ & $-0,59$ & 2,46 \\
\hline CHMP5 & chromatin modifying protein 5 & -0.58 & 0,64 & 0,84 & 0,22 & $-1,17$ \\
\hline CKS2 & CDC28 protein kinase regulatory subunit 2 & 0.23 & $-0,46$ & 0,96 & $-0,51$ & 2,34 \\
\hline CNOT1 & CCR4-NOT transcription complex, subunit 1 & -0.16 & 0,29 & 0,46 & $-2,46$ & $-0,26$ \\
\hline COL12A1 & collagen, type XII, alpha 1 & -0.02 & $-0,35$ & $-0,58$ & $-0,56$ & 1,98 \\
\hline COL5A1 & collagen, type $\mathrm{V}$, alpha 1 & -0.02 & 0,03 & $-0,75$ & $-0,50$ & 2,62 \\
\hline COX7B & $\begin{array}{l}\text { cytochrome } \mathrm{c} \text { oxidase subunit VIIb (COX7B), nuclear gene encoding } \\
\text { mitochondrial protein }\end{array}$ & 0.90 & $-0,65$ & $-1,01$ & $-0,55$ & 0,78 \\
\hline CPSF1 & cleavage and polyadenylation specific factor 1 & 0.11 & 0,46 & 2,77 & 0,01 & $-0,76$ \\
\hline CSNK1A1 & casein kinase 1 , alpha 1 & -0.95 & $-0,13$ & 0,76 & 1,00 & $-1,32$ \\
\hline CTSC & cathepsin C & -0.21 & $-0,13$ & 0,82 & $-1,24$ & 0,60 \\
\hline CXCL1 & chemokine (C-X-C motif) ligand 1 & -0.16 & 0,40 & 1,50 & 0,54 & $-2,04$ \\
\hline CXCL11 & chemokine (C-X-C motif) ligand 11 & 0.25 & 3,68 & 1,08 & 2,39 & $-3,82$ \\
\hline CXCL3 & chemokine (C-X-C motif) ligand 3 & 0.22 & 0,67 & 1,51 & 1,17 & $-1,95$ \\
\hline CYBRD1 & cytochrome b reductase 1 & 0.44 & $-0,47$ & $-0,53$ & 0,16 & 2,44 \\
\hline DDIT3 & DNA-damage-inducible transcript 3 & 0.38 & 0,11 & 1,15 & 3,33 & $-1,71$ \\
\hline DDX58 & DEAD (Asp-Glu-Ala-Asp) box polypeptide 58 & 0.07 & 1,38 & 0,47 & 1,54 & $-4,31$ \\
\hline DDX60 & DEAD (Asp-Glu-Ala-Asp) box polypeptide 60 & 0.27 & 0,95 & 1,01 & 3,21 & $-2,61$ \\
\hline DDX60L & DEAD (Asp-Glu-Ala-Asp) box polypeptide 60-like & 0.41 & 1,55 & 1,64 & 1,34 & $-3,61$ \\
\hline DEFB1 & defensin, beta 1 (DEFB1) & 0.05 & 0,39 & $-0,73$ & $-0,79$ & 3,20 \\
\hline DNAJC2 & DNAJC2 -- DnaJ (Hsp40) homolog, subfamily C, member 2 & 0.60 & $-1,86$ & $-0,37$ & 0,15 & $-0,63$ \\
\hline DNAJC25-GNG10 & DNAJC25-GNG10 readthrough & -0.29 & $-0,99$ & $-0,41$ & $-1,51$ & 0,92 \\
\hline DTX3L & deltex 3-like (Drosophila) & -0.07 & 0,77 & 0,62 & 1,00 & $-2,42$ \\
\hline DUSP4 & dual specificity phosphatase 4 & 0.27 & 0,13 & 1,09 & $-0,37$ & $-4,02$ \\
\hline DUSP6 & dual specificity phosphatase 6 & -0.17 & 0,91 & 0,08 & $-0,12$ & $-2,52$ \\
\hline EDARADD & EDAR-associated death domain & 0.88 & $-0,08$ & $-1,30$ & $-1,71$ & 0,24 \\
\hline EFEMP1 & EGF-containing fibulin-like extracellular matrix protein 1 & -0.19 & $-0,60$ & $-0,06$ & $-0,50$ & 3,17 \\
\hline EGFL8 & EGF-like-domain, multiple 8 & 0.64 & 0,68 & 2,31 & $-0,27$ & $-1,11$ \\
\hline EIF1 & eukaryotic translation initiation factor 1 & -0.31 & $-0,24$ & 0,75 & $-0,02$ & $-1,98$ \\
\hline EIF2AK2 & eukaryotic translation initiation factor 2-alpha kinase 2 & 0.47 & 0,14 & 1,00 & 0,65 & $-2,49$ \\
\hline EIF2C2 & eukaryotic translation initiation factor $2 \mathrm{C}$ & -0.74 & 0,40 & 1,62 & 1,68 & $-0,96$ \\
\hline EIF3L & eukaryotic translation initiation factor 3 , subunit L & 0.07 & $-1,07$ & $-0,26$ & $-0,97$ & 1,43 \\
\hline EMP2 & epithelial membrane protein 2 & 0.83 & 0,02 & $-0,64$ & $-0,33$ & 2,47 \\
\hline
\end{tabular}




\begin{tabular}{|c|c|c|c|c|c|c|}
\hline \multirow{2}{*}{ Gene symbol } & \multirow{2}{*}{ Gene name } & \multicolumn{5}{|c|}{ Fc } \\
\hline & & 0 hpi & 24 hpi & 48 hpi & 72 hpi & 96 hpi \\
\hline EPHX1 & epoxide hydrolase 1, microsomal (xenobiotic) & 0.50 & $-0,37$ & $-1,00$ & $-0,82$ & 1,52 \\
\hline ERMP1 & endoplasmic reticulum metallopeptidase 1 & 0.07 & $-0,77$ & $-0,70$ & $-0,52$ & 1,70 \\
\hline ETV4 & ets variant 4 & 0.91 & $-1,29$ & $-0,23$ & 0,72 & $-1,85$ \\
\hline F3 & coagulation factor III (thromboplastin, tissue factor) & 0.34 & 1,78 & 1,44 & 1,66 & $-1,79$ \\
\hline FAM3C & family with sequence similarity 3 , member $\mathrm{C}$ & -0.12 & 0,82 & 0,79 & 1,29 & $-2,02$ \\
\hline FN1 & fibronectin 1 & -0.01 & 2,07 & $-0,61$ & 2,49 & 0,30 \\
\hline FOLR1 & folate receptor 1 & -0.17 & $-0,48$ & $-0,72$ & $-0,86$ & 2,43 \\
\hline FOSL1 & FOS-like antigen 1 & 0.36 & 0,59 & 0,33 & 1,37 & $-2,09$ \\
\hline FST & follistatin & -0.10 & 1,36 & 2,66 & 2,02 & $-6,89$ \\
\hline GARS & glycyl-tRNA synthetase & 0.51 & $-0,20$ & 0,24 & 0,52 & $-2,02$ \\
\hline GBP1 & guanylate binding protein 1 , interferon-inducible, $67 \mathrm{kDa}$ & -0.08 & 1,60 & 2,07 & 0,41 & $-2,87$ \\
\hline GBP3 & guanylate binding protein 3 & -0.27 & 0,62 & 0,66 & 1,12 & $-1,57$ \\
\hline GCNT3 & glucosaminyl (N-acetyl) transferase 3 , mucin type & -0.13 & 0,25 & 0,29 & 0,86 & $-2,22$ \\
\hline GDF15 & growth differentiation factor 15 & -0.10 & 0,16 & 0,23 & 0,42 & $-4,37$ \\
\hline GLA & galactosidase, alpha & -0.96 & $-0,20$ & 1,50 & $-0,12$ & 1,20 \\
\hline GMNN & geminin, DNA replication inhibitor & 0.37 & 0,34 & $-0,05$ & $-0,38$ & 1,88 \\
\hline GPR109A & G protein-coupled receptor $109 \mathrm{~A}$ & -0.09 & $-0,46$ & $-1,00$ & 0,02 & 3,62 \\
\hline GPR109B & G protein-coupled receptor $109 \mathrm{~B}$ & 0.03 & $-0,53$ & $-1,29$ & $-0,27$ & 3,18 \\
\hline GSG1 & germ cell associated 1 & -0.91 & 0,14 & $-0,96$ & 0,19 & 2,49 \\
\hline GTPBP2 & GTP binding protein 2 & -0.59 & 0,73 & 0,25 & 1,26 & $-2,44$ \\
\hline H19 & imprinted maternally expressed transcript & -0.16 & $-0,55$ & $-0,28$ & $-0,42$ & 2,82 \\
\hline H1F0 & H1 histone family, member 0 & 0.31 & $-0,28$ & 2,70 & 1,12 & $-2,73$ \\
\hline HADHB & hydroxyacyl-CoA dehydrogenase, beta subunit & 0.39 & $-0,40$ & $-1,39$ & $-0,16$ & 1,36 \\
\hline HBEGF & heparin-binding EGF-like growth factor & -0.66 & 1,68 & 1,95 & 1,81 & $-3,87$ \\
\hline HDAC9 & histone deacetylase 9 & 0.57 & 0,07 & 0,11 & 0,96 & $-2,48$ \\
\hline HERC5 & hect domain and RLD 5 & -0.01 & 2,83 & 0,61 & 2,05 & $-3,15$ \\
\hline HERC6 & hect domain and RLD 6 & 0.74 & 0,91 & 0,76 & 1,12 & $-3,44$ \\
\hline HIST1H1B & histone cluster $1, \mathrm{H} 1 \mathrm{~b}$ & -0.42 & 0,46 & $-1,12$ & $-0,42$ & 3,51 \\
\hline HIST1H2AJ & histone cluster 1, H2aj & -0.54 & $-0,20$ & $-0,45$ & 0,31 & 2,09 \\
\hline HIST1H3I & histone cluster $1, \mathrm{H} 3 \mathrm{i}$ & -0.55 & 0,23 & $-0,59$ & 0,17 & 1,64 \\
\hline HIST1H4C & histone cluster $1, \mathrm{H} 4 \mathrm{c}$ & 0.33 & $-0,43$ & $-0,92$ & $-0,13$ & 2,54 \\
\hline HLA-A & major histocompatibility complex, class I, A & 0.17 & 2,14 & 3,80 & 3,42 & $-4,62$ \\
\hline hLA-B & major histocompatibility complex, class I, B & -0.35 & 2,09 & 2,73 & 3,02 & $-4,19$ \\
\hline HLA-C & major histocompatibility complex, class I, C & -0.26 & 1,68 & 3,06 & 2,16 & $-3,80$ \\
\hline HLA-E & major histocompatibility complex, class I, E & 0.01 & 1,63 & 2,93 & 2,62 & $-3,28$ \\
\hline HLA-F & major histocompatibility complex, class I, F & -0.28 & 1,67 & 2,25 & 1,97 & $-3,48$ \\
\hline HLA-G & major histocompatibility complex, class I, G & -0.03 & 1,13 & 1,54 & 2,29 & $-3,29$ \\
\hline HLA-H & major histocompatibility complex, class I, H & -0.17 & 1,56 & 2,67 & 1,19 & $-3,66$ \\
\hline HMGA1 & high mobility group AT-hook 1 & 0.06 & 0,12 & $-0,15$ & $-0,03$ & $-0,42$ \\
\hline HMGB2 & high-mobility group box 2 & 0.83 & $-0,38$ & 0,29 & $-0,11$ & 2,21 \\
\hline HSPB8 & heat shock $22 \mathrm{kDa}$ protein 8 & -0.14 & $-0,44$ & $-0,92$ & 0,21 & 3,02 \\
\hline HTRA2 & HtrA serine peptidase 2 & -0.09 & 0,08 & 1,72 & $-0,10$ & $-0,49$ \\
\hline ID1 & inhibitor of DNA binding 1 & -0.13 & $-0,17$ & $-1,41$ & $-0,42$ & 2,87 \\
\hline ID3 & inhibitor of DNA binding 3 & -0.19 & $-0,82$ & $-0,37$ & $-0,56$ & 3,21 \\
\hline IER3 & immediate early response 3 & 0.03 & 1,64 & 1,20 & 0,94 & $-2,83$ \\
\hline IER5 & immediate early response 5 & 0.40 & 0,36 & $-0,03$ & 1,10 & $-1,12$ \\
\hline IFI35 & interferon-induced protein 35 & 0.13 & 1,93 & 0,48 & 0,93 & $-2,93$ \\
\hline IFI44 & interferon-induced protein 44 & 0.08 & 4,74 & 1,61 & 3,41 & $-5,55$ \\
\hline IFI44L & interferon-induced protein 44 -like & -0.06 & 0,41 & 1,21 & 0,21 & $-4,17$ \\
\hline IFI6 & interferon, alpha-inducible protein 6 & -0.25 & 0,55 & 0,66 & 0,18 & $-3,30$ \\
\hline IFIH1 & interferon induced with helicase $\mathrm{C}$ domain 1 & 0.26 & 2,20 & 1,67 & 2,33 & $-4,14$ \\
\hline IFIT1 & interferon-induced protein with tetratricopeptide repeats 1 & -0.36 & 6,13 & 2,54 & 2,73 & $-6,42$ \\
\hline IFIT3 & interferon-induced protein with tetratricopeptide repeats 3 & 0.12 & 1,72 & 0,31 & 2,30 & $-3,27$ \\
\hline
\end{tabular}




\begin{tabular}{|c|c|c|c|c|c|c|}
\hline \multirow{2}{*}{ Gene symbol } & \multirow{2}{*}{ Gene name } & \multicolumn{5}{|c|}{ Fc } \\
\hline & & O hpi & 24 hpi & 48 hpi & 72 hpi & $96 \mathrm{hpi}$ \\
\hline IFIT5 & interferon-induced protein with tetratricopeptide repeats 5 & -0.26 & 1,15 & $-0,98$ & 0,97 & $-2,46$ \\
\hline IFITM1 & interferon induced transmembrane protein 1 (9-27) (IFITM1) & -0.11 & 1,86 & 1,78 & 1,32 & $-2,86$ \\
\hline IFRD1 & interferon-related developmental regulator 1 (IFRD1), transcript variant 2 & 0.09 & 0,60 & 0,10 & 0,86 & $-1,76$ \\
\hline IGFBP1 & insulin-like growth factor binding protein 1 (IGFBP1). & 0.57 & 1,54 & $-1,65$ & $-0,19$ & 0,03 \\
\hline IGFBP3 & insulin-like growth factor binding protein 3 (IGFBP3), transcript variant 2 & 0.13 & 0,39 & 1,45 & 0,66 & $-1,84$ \\
\hline IL1A & interleukin 1, alpha (IL1A) & 0.53 & 1,28 & 0,17 & 0,79 & $-1,79$ \\
\hline IL1RL1 & interleukin 1 receptor-like 1 (IL1RL1), transcript variant 1 & 0.37 & 1,49 & $-0,06$ & $-0,49$ & $-0,77$ \\
\hline IL23A & interleukin 23 , alpha subunit p19 & 0.20 & 1,49 & 0,09 & 1,48 & $-1,56$ \\
\hline IL24 & interleukin 24 (IL24), transcript variant 5 & -0.14 & 1,03 & 1,49 & 0,35 & $-3,69$ \\
\hline IL6 & interleukin 6 (interferon, beta 2) (IL6) & 0.47 & 1,08 & 0,84 & 1,46 & $-2,78$ \\
\hline IL8 & interleukin 8 & 0.11 & 1,13 & 1,40 & 1,31 & $-3,00$ \\
\hline INHA & inhibin, alpha & -0.54 & $-2,11$ & 0,57 & $-0,09$ & 2,29 \\
\hline IRF7 & interferon regulatory factor 7 & -0.62 & 1,86 & 0,31 & 1,50 & $-1,77$ \\
\hline IRF9 & interferon regulatory factor 9 & 0.28 & 1,66 & 0,70 & 2,18 & $-3,44$ \\
\hline ISG15 & ISG15 ubiquitin-like modifier & -0.54 & 2,35 & 1,45 & 3,42 & $-6,86$ \\
\hline ISG20 & interferon stimulated exonuclease gene $20 \mathrm{kDa}$ & 0.30 & 2,42 & 0,60 & 3,50 & $-3,51$ \\
\hline ISPD & isoprenoid synthase domain containing & 0.10 & $-0,23$ & 2,33 & $-0,27$ & $-0,26$ \\
\hline ITGB1 & integrin, beta 1 & 0.51 & 1,11 & 0,64 & 0,18 & $-1,34$ \\
\hline KCNJ1 & potassium inwardly-rectifying channel, subfamily J, member 1 & 0.10 & 0,66 & 1,69 & 0,94 & $-2,87$ \\
\hline KIAA0182 & KIAA0182 & -0.57 & 0,01 & 1,84 & $-0,23$ & $-0,39$ \\
\hline KIF20A & kinesin family member $20 \mathrm{~A}$ & 0.81 & $-0,53$ & $-0,97$ & $-0,67$ & 0,87 \\
\hline KLF5 & Kruppel-like factor 5 (intestinal) & 0.18 & 0,54 & 1,01 & 0,87 & $-1,37$ \\
\hline KPNA2 & karyopherin alpha 2 ( importin alpha 1 ) & 0.36 & 0,06 & $-0,06$ & $-0,09$ & 2,31 \\
\hline KRTAP4-6 & keratin associated protein 4-6 & 0.41 & 0,50 & $-1,59$ & 0,17 & $-0,67$ \\
\hline LAMC2 & laminin, gamma 2 & 0.20 & 4,02 & 0,11 & 2,28 & $-1,36$ \\
\hline LAMP3 & lysosomal-associated membrane protein 3 & 0.38 & 3,03 & 0,97 & 1,08 & $-3,22$ \\
\hline LAP3 & leucine aminopeptidase 3 & 0.11 & 0,70 & 0,85 & 0,14 & $-2,14$ \\
\hline LCN2 & lipocalin 2 & -0.09 & 0,56 & 2,17 & 0,68 & $-2,67$ \\
\hline LDLR & low density lipoprotein receptor & -0.39 & 0,24 & 0,83 & 1,06 & $-2,08$ \\
\hline LGALS3BP & lectin, galactoside-binding, soluble, 3 binding protein & -0.19 & 0,35 & 1,44 & 0,44 & $-2,12$ \\
\hline LGALS9 & lectin, galactoside-binding, soluble, 9 & 0.12 & 1,37 & 0,41 & 0,76 & $-2,55$ \\
\hline LIF & leukemia inhibitory factor (cholinergic differentiation factor) & 0.17 & 0,59 & 0,36 & 1,14 & $-1,81$ \\
\hline LRP1 & low density lipoprotein receptor-related protein 1 & -0.20 & $-0,60$ & $-0,95$ & $-0,13$ & 1,54 \\
\hline MAFK & v-maf musculoaponeurotic fibrosarcoma oncogene homolog K & -0.09 & 0,30 & 0,70 & 1,11 & $-1,81$ \\
\hline MAP2 & microtubule-associated protein 2 & -0.60 & $-1,20$ & 0,26 & 1,12 & 1,30 \\
\hline MAPK8 & mitogen-activated protein kinase 8 & 0.75 & $-0,39$ & $-0,58$ & $-0,35$ & 1,41 \\
\hline MARS & methionyl-tRNA synthetase & 0.15 & $-0,28$ & 2,70 & 1,12 & $-2,70$ \\
\hline MBOAT7 & membrane bound $\mathrm{O}$-acyltransferase domain containing 7 & 0.59 & $-0,09$ & $-1,31$ & $-0,20$ & 1,19 \\
\hline MDK & midkine (neurite growth-promoting factor 2) & 0.17 & 0,52 & 1,26 & 0,40 & $-1,36$ \\
\hline MDM2 & Mdm2 p53 binding protein homolog & -0.05 & $-0,18$ & 0,79 & 0,92 & $-2,05$ \\
\hline METTL7A & methyltransferase like 7A & 0.41 & $-0,59$ & $-0,07$ & $-0,80$ & 2,29 \\
\hline MFF & mitochondrial fission factor & 0.16 & $-0,90$ & 0,75 & $-0,49$ & 1,23 \\
\hline MGST1 & microsomal glutathione S-transferase 1 & 0.35 & $-0,19$ & $-1,24$ & $-0,88$ & 1,38 \\
\hline MICAL2 & $\begin{array}{l}\text { microtubule associated monoxygenase, calponin and LIM domain } \\
\text { containing } 2\end{array}$ & 0.63 & 0,91 & 0,81 & 0,70 & $-2,52$ \\
\hline MLKL & mixed lineage kinase domain-like & -0.68 & $-0,07$ & 0,93 & 0,55 & $-1,68$ \\
\hline MMP1 & matrix metallopeptidase 1 (interstitial collagenase) & 0.72 & 3,38 & 0,66 & 0,83 & $-3,20$ \\
\hline MOCOS & molybdenum cofactor sulfurase & 0.04 & $-0,18$ & 0,58 & 1,31 & $-1,97$ \\
\hline MSH6 & mutS homolog 6 & 0.11 & 0,10 & $-0,03$ & $-1,50$ & 0,83 \\
\hline MST1R & MST1R - macrophage stimulating 1 receptor (c-met-related tyrosine kinase) & -0.42 & 1,42 & $-0,15$ & 0,33 & $-1,36$ \\
\hline MT1DP & metallothionein 1D (pseudogene) & -0.29 & $-0,35$ & $-1,86$ & $-0,91$ & 1,75 \\
\hline MT1E & metallothionein $1 \mathrm{E}$ & 0.31 & $-0,72$ & $-0,68$ & $-0,51$ & 2,28 \\
\hline
\end{tabular}




\begin{tabular}{|c|c|c|c|c|c|c|}
\hline \multirow{2}{*}{ Gene symbol } & \multirow{2}{*}{ Gene name } & \multicolumn{5}{|c|}{ Fc } \\
\hline & & 0 hpi & 24 hpi & 48 hpi & 72 hpi & 96 hpi \\
\hline MT1M & metallothionein $1 \mathrm{M}$ & 0.10 & $-0,83$ & $-0,50$ & $-1,23$ & 2,50 \\
\hline MTHFD2 & $\begin{array}{l}\text { methylenetetrahydrofolate dehydrogenase (NADP+ dependent) } 2 \text {, } \\
\text { methenyltetrahydrofolate cyclohydrolase }\end{array}$ & 0.02 & 0,49 & 0,86 & 0,69 & $-2,65$ \\
\hline MT-TR & mitochondrially encoded tRNA arginine & 0.38 & 0,30 & 2,41 & 0,72 & $-3,26$ \\
\hline MTX1 & $\operatorname{metaxin} 1$ & -0.16 & 0,16 & 3,12 & $-0,13$ & $-2,99$ \\
\hline MX1 & myxovirus (influenza virus) resistance 1 & -0.07 & 4,55 & 3,36 & 1,70 & $-6,31$ \\
\hline MX2 & myxovirus (influenza virus) resistance 2 & -0.61 & 2,24 & 0,98 & 1,26 & $-4,58$ \\
\hline MXRA5 & matrix-remodelling associated 5 & 0.04 & $-1,32$ & $-1,01$ & $-1,58$ & 3,44 \\
\hline MYD88 & myeloid differentiation primary response gene (88) & 0.86 & $-0,73$ & 0,52 & 0,92 & $-1,73$ \\
\hline MYO9A & myosin IXA & -0.06 & $-0,20$ & $-2,38$ & 0,22 & 0,82 \\
\hline NAMPT & nicotinamide phosphoribosyltransferase & 0.15 & 0,37 & 1,12 & 0,92 & $-2,56$ \\
\hline NCAPG2 & non-SMC condensin II complex, subunit G2 & -0.19 & $-0,06$ & $-1,11$ & 0,01 & 2,38 \\
\hline NMI & $\mathrm{N}$-myc (and STAT) interactor & 0.25 & 1,09 & 0,15 & 0,41 & $-2,85$ \\
\hline NNMT & nicotinamide $\mathrm{N}$-methyltransferase & 0.10 & $-1,46$ & $-0,36$ & $-0,58$ & 1,83 \\
\hline NNT & nicotinamide nucleotide transhydrogenase & -0.14 & $-1,00$ & 0,14 & $-0,67$ & 1,43 \\
\hline NOTCH3 & notch 3 & 0.11 & $-1,29$ & $-0,66$ & 0,09 & 2,32 \\
\hline NPC2 & Niemann-Pick disease, type C2 & 0.01 & $-0,01$ & $-0,82$ & $-0,26$ & 2,01 \\
\hline NT5DC2 & 5 '-nucleotidase domain containing 2 & -0.71 & $-0,09$ & $-0,55$ & $-0,25$ & 1,41 \\
\hline NUSAP1 & nucleolar and spindle associated protein 1 & 0.25 & 0,08 & $-0,23$ & $-0,35$ & 3,39 \\
\hline OAS1 & 2',5'-oligoadenylate synthetase 1 & -0.41 & 3,41 & 2,43 & 2,79 & $-5,90$ \\
\hline OAS2 & 2'-5'-oligoadenylate synthetase $2,69 / 71 \mathrm{kDa}$ & -0.05 & 2,56 & 3,07 & 1,09 & $-6,96$ \\
\hline OAS3 & 2'-5'-oligoadenylate synthetase $3,100 \mathrm{kDa}$ & 0.27 & 2,11 & 1,93 & 1,27 & $-4,54$ \\
\hline OASL & 2'-5'-oligoadenylate synthetase-like & 0.20 & 2,37 & 0,63 & 2,16 & $-5,11$ \\
\hline OCRL & oculocerebrorenal syndrome of Lowe & -0.14 & $-0,10$ & $-2,50$ & $-0,32$ & $-0,68$ \\
\hline OLR1 & oxidized low density lipoprotein (lectin-like) receptor 1 & 0.37 & $-0,99$ & $-1,21$ & $-0,40$ & 2,30 \\
\hline OSTM1 & osteopetrosis associated transmembrane protein 1 & 0.80 & $-0,03$ & 1,78 & 0,14 & $-1,34$ \\
\hline PARP14 & poly (ADP-ribose) polymerase family, member 14 & 0.09 & 0,33 & 0,48 & 1,84 & $-2,27$ \\
\hline PARP9 & poly (ADP-ribose) polymerase family, member 9 & -0.12 & 1,73 & $-0,16$ & 0,68 & $-2,52$ \\
\hline PATL1 & protein associated with topoisomerase II homolog 1 & -0.20 & 0,47 & 0,41 & 0,43 & $-2,19$ \\
\hline PCSK9 & proprotein convertase subtilisin/kexin type 9 & 0.00 & $-0,99$ & $-0,22$ & 1,85 & $-1,14$ \\
\hline PDE4B & phosphodiesterase 4B, cAMP-specific & -0.46 & $-1,07$ & 0,65 & 0,59 & $-2,24$ \\
\hline PER2 & PER2 - period homolog 2 & -0.26 & 0,10 & 1,81 & 0,10 & $-0,78$ \\
\hline PERP & PERP - PERP, TP53 apoptosis effector & -0.13 & $-0,37$ & $-0,99$ & 0,00 & 1,29 \\
\hline PHLDA1 & PHLDA1 - pleckstrin homology-like domain, family A, member 1 & 0.23 & 0,42 & 0,31 & 1,31 & $-2,22$ \\
\hline PHTF2 & putative homeodomain transcription factor 2 & -0.26 & 0,58 & $-0,61$ & $-0,70$ & 3,58 \\
\hline PLAUR & plasminogen activator, urokinase receptor & -0.42 & 1,37 & $-0,07$ & 1,49 & $-1,76$ \\
\hline PLSCR1 & phospholipid scramblase 1 (PLSCR1). & 0.96 & 1,01 & 0,85 & 0,81 & $-3,16$ \\
\hline PLUNC & palate, lung and nasal epithelium associated & 0.21 & $-0,19$ & 2,70 & $-0,16$ & $-5,69$ \\
\hline PMAIP1 & phorbol-12-myristate-13-acetate-induced protein 1 & 0.25 & 1,11 & 1,40 & 3,17 & $-3,17$ \\
\hline PPM1K & protein phosphatase, $\mathrm{Mg} 2+/ \mathrm{Mn} 2+$ dependent, $1 \mathrm{~K}$ & 0.40 & 0,60 & $-0,98$ & 0,34 & $-1,76$ \\
\hline PPP1R15A & protein phosphatase 1 , regulatory (inhibitor) subunit 15A & -0.17 & 0,86 & $-0,35$ & 3,02 & $-2,71$ \\
\hline PRC1 & protein regulator of cytokinesis 1 & -0.40 & $-0,43$ & 0,64 & $-0,12$ & 1,69 \\
\hline PRIC285 & peroxisomal proliferator-activated receptor A interacting complex 285 & -0.20 & 2,59 & $-0,21$ & 1,37 & $-4,12$ \\
\hline PRKAR2B & protein kinase, cAMP-dependent, regulatory, type II, beta & -0.21 & 0,44 & 0,39 & 0,67 & $-1,65$ \\
\hline PRKD2 & protein kinase D2 & 0.12 & 1,02 & $-1,27$ & 0,47 & $-1,29$ \\
\hline PROM2 & prominin 2 & -0.15 & $-0,64$ & $-0,51$ & $-0,30$ & 1,93 \\
\hline PRSS23 & protease, serine, 23 & 0.01 & 0,14 & $-0,94$ & 1,27 & 1,43 \\
\hline PSIP1 & PC4 and SFRS1 interacting protein 1 & 0.74 & $-0,10$ & $-1,04$ & $-3,30$ & 1,49 \\
\hline PSMB8 & proteasome (prosome, macropain) subunit, beta type, 8 & 0.26 & 1,03 & 0,44 & 0,04 & $-1,45$ \\
\hline PSMB9 & proteasome (prosome, macropain) subunit, beta type, 9 & -0.01 & 1,47 & $-0,07$ & 1,42 & $-1,65$ \\
\hline PTGS2 & prostaglandin-endoperoxide synthase 2 & 0.37 & 0,76 & 1,80 & 0,97 & $-3,28$ \\
\hline PTPRF & protein tyrosine phosphatase, receptor type, $\mathrm{F}$ & 0.16 & $-0,38$ & $-1,05$ & $-0,21$ & 2,32 \\
\hline RAB31 & RAB31, member RAS oncogene family & 0.15 & 0,40 & 0,60 & 0,87 & $-1,62$ \\
\hline
\end{tabular}




\begin{tabular}{|c|c|c|c|c|c|c|}
\hline \multirow{2}{*}{ Gene symbol } & \multirow{2}{*}{ Gene name } & \multicolumn{5}{|c|}{ Fc } \\
\hline & & o hpi & 24 hpi & 48 hpi & 72 hpi & 96 hpi \\
\hline RAB3IL1 & RAB3A interacting protein (rabin3)-like 1 & 0.26 & 0,63 & 2,32 & 0,21 & $-1,40$ \\
\hline RAP1GAP2 & RAP1 GTPase activating protein 2 & 0.47 & 1,18 & $-0,64$ & 0,61 & $-5,28$ \\
\hline RCN2 & reticulocalbin 2 & 0.15 & 0,06 & $-0,26$ & $-2,04$ & 0,70 \\
\hline REC8 & REC8 homolog & 0.65 & 2,08 & 0,67 & 0,91 & $-1,60$ \\
\hline RHOV & ras homolog gene family, member $\mathrm{V}$ & 0.12 & $-0,24$ & $-1,41$ & $-0,47$ & 1,28 \\
\hline RICTOR & RPTOR independent companion of MTOR, complex 2 & 0.83 & 0,67 & 1,84 & 0,86 & $-2,53$ \\
\hline RNF19B & ring finger protein 19B & 0.23 & 0,54 & 0,43 & 0,03 & $-1,83$ \\
\hline RPA1 & replication protein $\mathrm{A} 1,70 \mathrm{kDa}$ & 0.53 & $-0,78$ & 0,59 & $-0,09$ & 1,51 \\
\hline RPL7 & ribosomal protein L7 & -0.10 & $-0,75$ & $-0,83$ & $-1,71$ & 0,75 \\
\hline RRM1 & ribonucleotide reductase $\mathrm{M} 1$ & 0.22 & $-0,38$ & $-0,75$ & $-0,82$ & 2,19 \\
\hline S100A8 & S100 calcium binding protein A8 & 0.04 & 0,52 & 1,88 & 0,04 & $-3,26$ \\
\hline S100A9 & S100 calcium binding protein A9 & -0.08 & 0,01 & 2,27 & $-0,31$ & $-1,63$ \\
\hline SAMD9L & sterile alpha motif domain containing 9-like & 0.43 & 1,47 & $-0,86$ & $-0,53$ & $-2,21$ \\
\hline SAMHD1 & SAM domain and HD domain 1 & -0.60 & 1,28 & 0,21 & 1,23 & $-3,23$ \\
\hline SAV1 & salvador homolog 1 & -0.20 & 0,20 & 0,41 & 0,92 & $-2,02$ \\
\hline SCD5 & stearoyl-CoA desaturase 5 & -0.18 & 0,11 & $-1,34$ & $-0,24$ & 1,04 \\
\hline SCPEP1 & serine carboxypeptidase 1 & -0.02 & $-0,43$ & 0,38 & $-0,19$ & 2,29 \\
\hline SERPINB4 & serpin peptidase inhibitor, clade B (ovalbumin), member 4 & 0.00 & $-0,50$ & 0,05 & $-2,37$ & 0,03 \\
\hline SHMT2 & serine hydroxymethyltransferase 2 & 0.12 & $-0,56$ & 1,00 & $-0,18$ & $-1,52$ \\
\hline SHROOM3 & shroom family member 3 & -0.17 & 0,02 & 0,29 & 0,90 & $-1,39$ \\
\hline SLC16A2 & solute carrier family 16 , member 2 & 0.28 & $-0,38$ & $-0,62$ & 0,10 & 2,36 \\
\hline SLC30A7 & solute carrier family 30 , member 7 & -0.22 & $-0,18$ & $-0,22$ & 3,08 & $-1,46$ \\
\hline SLC6A14 & solute carrier family 6 , member 14 & 0.76 & 0,06 & 0,53 & 0,37 & $-2,17$ \\
\hline SLC6A9 & solute carrier family 6 , member 9 & -0.13 & 0,19 & 0,03 & 0,37 & $-2,37$ \\
\hline SMOX & spermine oxidase & -0.55 & $-0,13$ & 0,33 & 0,20 & $-1,87$ \\
\hline SNCG & synuclein, gamma & 0.20 & $-1,16$ & $-0,86$ & 0,06 & 2,55 \\
\hline SOX9 & SRY (sex determining region Y)-box 9 & -0.28 & 0,96 & $-0,25$ & 2,00 & $-2,37$ \\
\hline SP110 & SP110 nuclear body protein & -0.26 & 0,78 & 0,75 & 0,59 & $-2,22$ \\
\hline SPAG5 & sperm associated antigen 5 & 0.36 & $-0,12$ & $-0,71$ & 0,06 & 2,31 \\
\hline SQRDL & sulfide quinone reductase-like & 0.17 & 0,60 & $-0,02$ & 0,88 & $-1,46$ \\
\hline ST6GALNAC2 & $\begin{array}{l}\text { ST6 (alpha-N-acetyl-neuraminyl-2,3-beta-galactosyl-1, 3)- } \\
\text { N-acetylgalactosaminide alpha-2,6-sialyltransferase } 2\end{array}$ & 0.50 & $-0,33$ & 0,76 & $-0,07$ & 2,16 \\
\hline STAG3L3 & stromal antigen 3 -like 3 & -0.70 & 0,13 & $-0,68$ & $-1,25$ & 1,17 \\
\hline STAT1 & signal transducer and activator of transcription $1,91 \mathrm{kDa}$ & -0.10 & 2,40 & 1,59 & 0,71 & $-3,83$ \\
\hline STAT2 & signal transducer and activator of transcription $2,113 \mathrm{kDa}$ & 0.12 & 1,39 & 1,68 & 0,84 & $-1,89$ \\
\hline STC1 & Stanniocalcin 1 & 0.19 & 1,70 & 1,35 & 0,86 & $-5,39$ \\
\hline STC2 & stanniocalcin 2 & 0.55 & 1,33 & 1,36 & 1,01 & $-2,75$ \\
\hline STK40 & serine/threonine kinase 40 & 0.16 & 0,21 & 0,32 & 0,35 & $-1,61$ \\
\hline STMN1 & stathmin 1 & -0.32 & 0,15 & $-0,55$ & $-0,32$ & 2,59 \\
\hline SYNE2 & spectrin repeat containing, nuclear envelope 2 & -0.25 & $-0,02$ & $-0,78$ & 0,03 & 1,80 \\
\hline SYNPO & synaptopodin & 0.05 & $-0,95$ & $-0,93$ & $-0,18$ & 1,58 \\
\hline TACC2 & transforming, acidic coiled-coil containing protein 2 & -0.03 & $-0,89$ & 0,03 & $-0,12$ & 2,19 \\
\hline TAP1 & transporter 1, ATP-binding cassette, sub-family B & 0.11 & 1,90 & 0,76 & 5,68 & $-2,68$ \\
\hline TARS & threonyl-tRNA synthetase & 0.30 & 0,04 & 1,16 & 0,44 & $-1,16$ \\
\hline TBC1D7 & TBC1 domain family, member 7 & 0.05 & $-1,72$ & 0,72 & $-0,97$ & $-0,31$ \\
\hline TCEB3B & transcription elongation factor $\mathrm{B}$ polypeptide $3 \mathrm{~B}$ & -0.09 & 0,58 & 1,06 & 1,04 & $-2,32$ \\
\hline TCF7 & transcription factor 7 (T-cell specific, HMG-box) & 0.27 & 0,25 & 2,10 & 0,67 & $-2,40$ \\
\hline TCTN1 & tectonic family member 1 & -0.46 & $-1,65$ & $-0,51$ & 0,88 & 0,70 \\
\hline TECR & trans-2,3-enoyl-CoA reductase & 0.24 & $-0,93$ & $-0,97$ & $-0,50$ & 1,31 \\
\hline TFPI2 & tissue factor pathway inhibitor 2 & -0.01 & 0,47 & 0,18 & 2,00 & $-1,46$ \\
\hline TGFB2 & transforming growth factor, beta 2 & -0.24 & 0,32 & 0,52 & 0,93 & $-1,81$ \\
\hline TGIF1 & TGFB-induced factor homeobox 1 & 0.12 & $-0,14$ & 1,46 & 1,03 & $-1,87$ \\
\hline TK1 & thymidine kinase 1 & 0.32 & $-0,61$ & $-0,58$ & $-0,09$ & 2,66 \\
\hline
\end{tabular}




\begin{tabular}{|c|c|c|c|c|c|c|}
\hline \multirow{2}{*}{ Gene symbol } & \multirow{2}{*}{ Gene name } & \multicolumn{5}{|c|}{ Fc } \\
\hline & & 0 hpi & 24 hpi & 48 hpi & 72 hpi & 96 hpi \\
\hline TLN1 & talin 1 & -0.40 & $-0,50$ & $-0,78$ & $-0,27$ & 1,39 \\
\hline TLR9 & toll-like receptor 9 & -0.88 & $-0,20$ & $-1,54$ & $-0,55$ & 1,29 \\
\hline TMC5 & transmembrane channel-like 5 & 0.21 & 0,97 & $-0,35$ & 0,62 & $-3,24$ \\
\hline TMEM132A & transmembrane protein $132 \mathrm{~A}$ & 0.14 & 0,31 & $-0,86$ & 1,49 & $-1,52$ \\
\hline TMEM27 & transmembrane protein 27 & 0.78 & 0,67 & $-0,08$ & 0,86 & $-1,65$ \\
\hline TNFAIP3 & tumor necrosis factor, alpha-induced protein 3 & -0.65 & 0,53 & 1,29 & 1,69 & $-1,62$ \\
\hline TOP1 & topoisomerase (DNA) I & 0.59 & 0,34 & 0,71 & 0,95 & $-1,22$ \\
\hline TOP2A & topoisomerase (DNA) II alpha $170 \mathrm{kDa}$ & 0.09 & $-0,64$ & $-0,57$ & $-0,71$ & 3,93 \\
\hline TPBG & trophoblast glycoprotein & -0.10 & 0,46 & 1,23 & 0,59 & $-1,62$ \\
\hline TPX2 & TPX2, microtubule-associated, homolog (Xenopus laevis) & 0.14 & $-0,40$ & $-0,26$ & $-0,59$ & 3,20 \\
\hline TRAM1 & translocation associated membrane protein 1 & -0.03 & 0,15 & $-1,20$ & $-0,40$ & 1,32 \\
\hline TRAPPC1 & trafficking protein particle complex 1 & -0.31 & 0,06 & $-0,14$ & $-1,21$ & 1,32 \\
\hline TRIB3 & tribbles homolog 3 (Drosophila) & 0.12 & 0,47 & 0,47 & 1,24 & $-1,28$ \\
\hline TRIM14 & tripartite motif-containing 14 & -0.06 & 0,33 & 0,32 & 0,37 & $-2,18$ \\
\hline TRIM21 & tripartite motif-containing 21 & 0.54 & 1,24 & 1,40 & 0,82 & $-1,99$ \\
\hline TRIM22 & tripartite motif-containing 22 & -0.04 & 1,60 & $-0,35$ & 0,14 & $-2,44$ \\
\hline TRIM29 & tripartite motif-containing 29 & -0.08 & $-1,30$ & $-1,57$ & $-0,75$ & 1,66 \\
\hline TRIM5 & tripartite motif-containing 5 & 0.33 & 0,49 & 0,69 & 0,17 & $-1,56$ \\
\hline TSC22D1 & TSC22 domain family, member 1 & 0.20 & 0,36 & 0,80 & 0,85 & $-2,02$ \\
\hline TXNIP & thioredoxin interacting protein & 0.35 & 0,28 & 0,72 & 1,76 & $-0,77$ \\
\hline TXNRD1 & thioredoxin reductase 1 & -0.26 & 0,69 & 1,07 & 1,71 & $-1,52$ \\
\hline UBA7 & ubiquitin-like modifier activating enzyme 7 & -0.91 & 1,09 & 0,66 & $-0,13$ & $-0,82$ \\
\hline UBD & ubiquitin $\mathrm{D}$ & -0.39 & $-0,26$ & $-0,74$ & $-0,29$ & 3,53 \\
\hline UBE2C & ubiquitin-conjugating enzyme E2C & 0.32 & $-0,35$ & 0,03 & $-0,39$ & 2,32 \\
\hline UBE2L6 & ubiquitin-conjugating enzyme E2L 6 & 0.66 & 1,75 & 1,90 & 0,43 & $-3,32$ \\
\hline UIMC1 & ubiquitin interaction motif containing 1 & 0.18 & 0,49 & $-2,16$ & $-0,20$ & $-0,20$ \\
\hline UPK3B & uroplakin 3B & -0.26 & $-0,75$ & $-0,87$ & $-0,71$ & 2,02 \\
\hline USP18 & ubiquitin specific peptidase 18 & 0.23 & 1,04 & 0,94 & 0,44 & $-3,21$ \\
\hline UTRN & Utrophin & -0.23 & $-0,02$ & 0,04 & 0,19 & 2,11 \\
\hline VEGFA & vascular endothelial growth factor A & -0.23 & 0,49 & 1,30 & 0,37 & $-3,39$ \\
\hline WARS & tryptophanyl-tRNA synthetase & 0.53 & 1,57 & 1,14 & 1,75 & $-3,93$ \\
\hline WNT10A & wingless-type MMTV integration site family, member 10A & 0.01 & $-0,99$ & $-1,04$ & $-0,72$ & 2,07 \\
\hline WwOX & WW domain containing oxidoreductase & 0.35 & $-0,70$ & 0,03 & $-0,19$ & 1,78 \\
\hline XPOT & exportin & 0.57 & 0,35 & 0,57 & 0,59 & $-2,30$ \\
\hline YARS & tyrosyl-tRNA synthetase & 0.02 & $-0,31$ & 0,32 & 0,28 & $-2,03$ \\
\hline ZC3HAV1 & zinc finger CCCH-type, antiviral 1 & -0.07 & 0,33 & 0,32 & 0,19 & $-1,83$ \\
\hline ZFP36 & zinc finger protein $36, \mathrm{C} 3 \mathrm{H}$ type & -0.45 & 0,59 & 0,43 & 0,94 & $-1,23$ \\
\hline ZNF331 & zinc finger protein 331 & -0.21 & $-0,73$ & $-0,75$ & $-0,36$ & 2,08 \\
\hline ZNF587 & zinc finger protein 587 & 0.13 & 0,31 & $-0,25$ & $-0,18$ & 2,02 \\
\hline ZNF823 & zinc finger protein 823 & 0.93 & $-0,73$ & $-1,87$ & $-0,70$ & 2,03 \\
\hline ZNFX1 & zinc finger, NFX1-type containing 1 & 0.07 & 1,44 & 1,45 & 3,55 & $-3,07$ \\
\hline ZWINT & ZW10 interactor & -0.65 & $-0,10$ & 0,19 & 0,17 & 2,27 \\
\hline
\end{tabular}

